\title{
O PIB brasileiro nos séculos XIX e XX: duzentos anos de flutuações econômicas
}

Guilherme Tombolo ${ }^{1}$

Armando Vaz Sampaio ${ }^{2}$

Resumo: O objetivo desse trabalho é o de analisar o comportamento da série do PIB brasileiro entre 1820 e 2012 no que diz respeito ao seu comportamento cíclico e períodos de crescimento econômico. Outro objetivo que surgiu com o anterior foi o de estimar o PIB nominal e real do Brasil entre 1820 e 1899, dada a ausência de estimativas que cobrissem esse período de forma continua. Identificamos sete fases de crescimento do produto real agregado brasileiro. A taxa média do período como um todo (1820-2012, 193 anos) foi de 3,71\% a.a. (média ponderada pela duração dos períodos). Na análise do PIB per capita, identificamos seis fases de crescimento. A taxa média de crescimento do período como um todo foi de 2,93\% a.a. No que diz respeito à volatilidade dos ciclos, tal volatilidade foi em geral decrescente quando medida pelo desvio-padrão dos ciclos extraídos pelo Filtro HP.

Palavras-chave: Ciclos Econômicos; História Econômica do Brasil; Produto Interno Bruto (PIB) do Brasil.

JEL: E32; N16; E01.

1 Mestre em Desenvolvimento Econômico - PPGDE/UFPR. Doutorando em Desenvolvimento Econômico PPGDE/UFPR. E-mail: guilhermetombolo@hotmail.com

2 Doutor em Economia Aplicada - Esalq/USP. Professor Adjunto - Departamento de Economia UFPR e PPGDE/ UFPR. E-mail: avsampaio@ufpr.br 


\title{
Brazilian GDP in the nineteenth and twentieth centuries: two hundred years of economic fluctuations
}

\begin{abstract}
The aim of this paper is to analyze the behavior of the series of Brazilian GDP between 1820 and 2012 with regard to its cyclical behavior and periods of economic growth. Another goal that came with the previous one was to estimate the nominal and real Brazilian GDP between 1820 and 1899, given the absence of estimates which covered the period continuously. We identified seven phases of growth in Brazilian real GDP. The average rate for the period as a whole (18202012, 193 years) was 3.71\% pa (weighted average for the duration of periods). In the analysis of GDP per capita, we identified six phases of growth. The average growth rate for the period as a whole was $2.93 \%$ pa. With regard to the volatility of cycles, such volatility was generally decreasing as measured by standard deviation of the cycles extracted by the filter HP.
\end{abstract}

Keywords: Economic Cycles; Economic History of Brazil; Gross Domestic Product (GDP) of Brazil.

JEL: E32; N16; E01.

\section{Introdução}

A análise dos ciclos econômicos tem uma longa tradição na ciência econômica, tradição essa que remonta aos primórdios da disciplina com os trabalhos dos clássicos como Adam Smith, David Ricardo, Thomas Malthus, etc. No século XX, o estudo dos ciclos econômicos ganha novo impulso na esteira da grande depressão econômica da década de 1930. A análise das propriedades estatísticas dos ciclos econômicos também começou a receber atenção nessa época dada a recente disponibilidade de estatísticas econômicas regulares. Os autores Mitchell e Burns (1946) identificaram várias características dos ciclos econômicos da economia dos Estados Unidos, assim como o fez Kaldor (1961) para economias em geral.

O estudo de tais propriedades é importante tanto para fins de confrontação e teste de modelos macroeconômicos, quanto para a compilação de dados para a historiografia econômica. Neste trabalho em particular, objetivamos analisar o comportamento da série temporal do PIB brasileiro entre 1820 e 2012 no que diz respeito ao seu comportamento cíclico e seus distintos períodos de crescimento econômico. Naturalmente, outro objetivo que surgiu foi o de estimar o PIB nominal e real brasileiro entre 1820 e 1899, dada a ausência de estimativas que cobrissem esse período de forma continua. Estimamos também o PIB real em dólares internacionais de Geary-Khamis no período 
1820-1899, a fim de comparar nossas estimativas com as de Maddison (2006).

Outros autores como Furtado (1976), Leff (1972, 1991), Haddad \& Contador (1975) e Goldsmith (1986), enfrentaram a tarefa de obter estimativas do PIB ou da renda nacional brasileira no século XIX. Entretanto para se analisar o comportamento cíclico do PIB acreditamos que as nossas estimativas do PIB nominal e real para o período de 1820 a 1900 são mais acuradas e adequadas por se basearem no procedimento econométrico de análise de cointegração. No que diz respeito à análise das propriedades cíclicas do PIB brasileiro durante o século XIX ou parte dele, o trabalho de Araújo et al. (2008) é o único - que nós saibamos - em que se analisam os ciclos econômicos e o crescimento do produto brasileiro na tradição da teoria do ciclo de negócios. Fazem isso para o período 1850-2000, utilizando-se da estimativa do PIB brasileiro entre 1850 e 1899 de Goldsmith (1986) encadeadas à estimativa de Haddad (1978) em 1900 e às estimativas oficiais em 1947.

Este trabalho está dividido em cinco seções incluindo essa Introdução. $\mathrm{Na}$ seção 2, O PIB nominal e real do Brasil no século XIX - 1820/1900, nós procedemos a estimação do PIB nominal e real do Brasil. O PIB nominal foi obtido de uma regressão cointegrante do log natural do PIB nominal entre 1900 e 1946 contra o log natural da população, da receita geral do setor público, das exportações e importações de bens e do conceito de moeda M2. O PIB real, por sua vez, é obtido do deflacionamento do PIB nominal por um deflator implícito do PIB. Tal deflator foi estimado de uma regressão cointegrante do deflator implícito do PIB entre 1889 e 1930 contra índices de preços dos séculos XIX e XX.

Na seção 3, Comparações Internacionais, nós convertemos para dólares internacionais de Geary-Khamis o PIB real que nós estimamos na seção 2 a fim de comparar os nossos resultados com os de Maddison (2006). A conversão é feita por meio de uma regressão cointegrante para o período 1900-1946 do log do PIB brasileiro, medido em dólares internacionais de 2008, contra o $\log$ do PIB brasileiro em reais de 2008, o log do deflator implícito do PIB, e o log do índice de preços ao consumidor (CPI) dos Estados Unidos. Na seção 4, PIB brasileiro: períodos de crescimento e ciclos, nós fizemos uma breve análise do comportamento do produto brasileiro no período 1820-2012. Por fim, na seção 5 , Conclusões, nós relatamos os principais resultados alcançados no trabalho.

\section{O PIB nominal e real do Brasil no século XIX: 1820/1900}

É difícil estimar variáveis como o PIB para o século XIX devido à escassez 
de dados e estatísticas que embasem tais estimativas. No entanto existem estimativas indiretas do produto real do Brasil para esse período. A maioria delas se baseia em variáveis fiscais do governo federal, exportações e importações, agregados monetários, etc. Uma das primeiras estimativas é a de Furtado (1976:149), que estimou a taxa de crescimento da renda per capita para o Brasil como um todo em 1,5\% a.a. entre 1850 e 1900 e 2,3\% a.a. para a região cafeeira no mesmo período (Vale do Paraíba e oeste do Estado de São Paulo). Furtado se baseou em séries de comércio internacional e fez - na verdade - mais uma conjectura do que uma estimativa propriamente dita.

Entretanto essa conjectura de Furtado foi considerada demasiado otimista por não se conformar com outros estudos. Por exemplo, Coatsworth (1978: quadro 1 apud Abreu \& Lago 2012:4) estima o crescimento do PIB per capita em o,36\% a.a. no período $1800-1860$ e 0,40\% a.a. no período 1860-1910. Por sua vez, Maddison (2006:520) sugere um crescimento da renda per capita de $0,20 \%$ a.a. entre 1820 e 1870 e o,30\% a.a. entre 1870 e 1913, Engerman e Sokoloff (1997:270), também para a renda per capita, sugerem 0,40\% a.a. para 1800-1850 e-0,40\% a.a. para 1850-1913, esta última destoando sobremaneira de Maddison e de Coatsworth como ressaltado por Abreu e Lago (2012:4).

Extraindo o primeiro componente principal ${ }^{1}$ das séries de exportações, importações e gastos do Governo Central ${ }^{2}$, todos deflacionados, Contador \& Haddad (1975) estimam o crescimento do produto real per capita em o,86\% a.a. para o período 1861-1889 e 2,68\% para o produto real agregado no mesmo período. Para o período 1861-1900 as estimativas são -0,40\% a.a. per capita e 1,47\% a.a. agregado. Por outro lado, Leff (1991:capítulo 3) e Leff (1972) se utilizando da relação de trocas da teoria quantitativa da moeda, estima a taxa de crescimento média da renda real per capita entre 1822 e 1913 no intervalo de -0,3 a $0,8 \%$ a.a. A média desses valores é $0,25 \%$ a.a., portanto a renda per capita de 1913 seria apenas $25 \%$ maior do que o foi em 1822 segundo as conclusões de Leff. Empregando a mesma técnica usada por Leff $(1972,1991)$ e também se baseando em Maddison (2006) e Engerman e Sokoloff (1997), Castro \& Gonçalves (2010) estimam o crescimento da renda per capita no Brasil em o,44\% a.a. entre 1800 e 1850 , e 0,207\% a.a. entre 1851 e 1910.

Uma das estimativas mais citadas do produto brasileiro no século XIX é a feita por Goldsmith (1986). O professor Goldsmith (1986: 24) elaborou uma série "experimental" do produto interno bruto brasileiro a preços correntes tomando a média aritmética simples de quatro indicadores, a saber: índice de massa de salários, oferta nominal de moeda M2, exportações mais importações nominais, e gastos do Governo Central também em termos nominais. O índice de massa de salários foi obtido multiplicando um índice de salários pagos ${ }^{3}$ por um índice de população conforme Goldsmith (1986:33). Dado o índice obtido

1 Análise de Componentes Principais é uma técnica estatístico-matemática.

2 Governo Central corresponde ao "governo federal" ou ao governo da "União" hoje em dia.

3 Índice elaborado por Lobo (1971) tomando a média de salários pagos a 20 ocupações na cidade do Rio de Janeiro entre 1850 e 1930. 
pela média aritmética dos indicadores, este foi então encadeado às estimativas do professor Haddad (1978) em 1910 voltando até o ano de 1850, gerando assim uma estimativa do PIB nominal brasileiro para o período $1850-1910^{4}$.

Para obter o produto em termos reais ou a preços constantes, Goldsmith (1986:31) construiu um índice de preços “interno" para o período 1850-1913 baseado na média aritmética simples de quatro índices de preços calculados, de forma aproximada, por outros quatro autores ${ }^{5}$, sendo que tais índices de preços serão abordados mais adiante nesse trabalho. Dividindo a série de produto nominal pelo seu índice de preços internos, Goldsmith (1986:22-23, 82-83) obteve uma série do produto a preços constantes para o Brasil entre 1850 e 1910. Em preços constantes, o produto no agregado teria crescido a uma taxa de $2,32 \%$ a.a. entre 1850 e 1880 e $2,30 \%$ a.a. entre 1880 e 1910 , em termos per capita foi o,66\% a.a. para o período $1850-1880$ e 0,157\% a.a. para o período 1880 e 1910.

Porém as estimativas de Goldsmith (1986) são vistas com muitas reservas, entre outras coisas, por "se basear[em] num índice de preços inteiramente inadequado, além de depender de algumas hipóteses questionáveis sobre o funcionamento da (...) economia [do Brasil] no século passado". (IBGE EHB 1990: 88 apud ABREU \& LAGO 2012:4). Não obstante, optamos nesse trabalho por uma abordagem semelhante à de Goldsmith para se calcular o PIB nominal e real brasileiro no século XIX. Ao fazer isso, entretanto, procedemos de forma diferente empregando econometria ao invés de uma média simples das variáveis.

\subsection{Estimação do PIB nominal}

Nossa ideia foi estimar uma regressão cointegrante do log natural do PIB nominal calculado por Haddad (1978) entre 1900 e 1946 contra o log natural da população, da receita geral do setor público, das exportações e importações de bens e do conceito de moeda M2 (valores monetários em Contos de Réis). Os dados da população residente foram obtidos de Mortara (1941) em termos decenais para o período de 1770 a 1870 e do Ipeadata (2012) para o período 1872-2011, sendo que entre 1980 e 2011 os dados referem-se à estimativa da população residente em 10 de julho feitas pelo IBGE. Os dados de Mortara (1941) foram anualizados por interpolação cúbica e encadeados aos do Ipeadata (2012) ${ }^{6}$. Os dados completos da população estão no apêndice estatístico

\footnotetext{
4 De fato as estimativas de Haddad (1978) cobrem o período de 1900 a 1947, sendo que as estimativas oficiais do PIB brasileiro iniciaram-se em 1947. No entanto as estimativas de Haddad são menos confiáveis para o período 1900-1908/1910, embora sejam amplamente aceitas. O professor Goldsmith, por seu turno, preferiu encadear suas estimativas ao ano de 1910 e não ao de 1908.

5 Buescu (1973:223; 1977:125; 1979:27), Lobo (1971:260-62), Onody (1960:118, 394) e Randall (1977 apud Vieira 1947, 1981).

6 De fato, Mortara (1941) estimou a população brasileira decenalmente entre 1770 e 1919 e obteve estimativas anuais desta por meio da interpolação linear dos valores decenais. Nós optamos aqui pela interpolação cúbica porque essa produz uma série mais suave da evolução da população no país.
} 
desse trabalho, os dados decenais de população estão na Tabela 1.

TABELA 1 - POPULAÇÃO RESIDENTE NO BRASIL - 1770/2010

\begin{tabular}{l|c|c|c|c|c|c|c}
\hline Ano & População & Ano & População & Ano & População & Ano & População \\
\hline 1770 & 2.502 .000 & 1830 & 5.354 .000 & 1900 & 17.438 .434 & 1980 & 119.011 .052 \\
1780 & 2.841 .000 & 1840 & 6.233 .000 & 1920 & 30.635 .605 & 1991 & 144.825 .152 \\
1790 & 3.225 .000 & 1850 & 7.256 .000 & 1940 & 41.236 .315 & 1996 & 157.070 .163 \\
1800 & 3.660 .000 & 1860 & 8.448 .000 & 1950 & 51.944 .397 & 2000 & 169.799 .170 \\
1810 & 4.155 .000 & 1870 & 9.384 .000 & 1960 & 70.070 .457 & 2007 & 183.987 .291 \\
1820 & 4.717 .000 & 1872 & 10.112 .061 & 1970 & 93.134 .846 & 2010 & 190.732 .694 \\
\hline
\end{tabular}

Fonte: Para 1770-1870, Mortara (1941); e para 1872-2010, Ipeadata (2012).

Com relação às receitas do setor público, existem séries de receitas e despesas gerais do governo federal que retrocedem até 1823 . No que diz respeito a estados e municípios tais estatísticas são escassas para o século XIX. Entre os anos de 1819 e 1822, Gama (1823) traz dados esparsos sobre as receitas e despesas das províncias do recém-fundado Império do Brasil, o autor Carreira (1889, p. 98, 311, 338) mostra dados das receitas e despesas das três esferas de governo nos anos fiscais de 1823, 1855, e 1870, por sua vez Cavalcanti (1890, p. 279-280, 17-24) mostra tais dados nos anos fiscais de 1840 e de 1878 até 1888, esses valores estão na tabela 2 .

TABELA 2 - RECEITAS DO SETOR PÚBLICO POR ESFERAS DE GOVERNO $1821 / 1907^{*}$

\begin{tabular}{l|c|c|c|c|c}
\hline & $\begin{array}{c}\text { União } \\
\mathrm{A}\end{array}$ & $\begin{array}{c}\text { Províncias } \\
\mathrm{B}\end{array}$ & $\begin{array}{c}\text { Municípios } \\
\mathrm{C}\end{array}$ & $\begin{array}{c}\text { Setor Público } \\
\mathrm{D}\end{array}$ & $\begin{array}{c}\mathrm{E}=\mathrm{A} .100 / \mathrm{D} \\
\mathrm{E}\end{array}$ \\
\hline 1821 & 3.997 & 5.711 & $391^{* *}$ & $10.099^{* *}$ & $39,58^{* *}$ \\
1823 & 3.802 & 12.727 & $443^{* *}$ & $16.972^{* *}$ & $22,40^{* *}$ \\
$1840-41$ & 16.311 & 4.981 & $935^{* *}$ & $22.227^{* *}$ & $73,83^{* *}$ \\
$1854-1855$ & 36.985 & 8.323 & 1.603 & 46.911 & 78,84 \\
$1859-1860$ & 43.807 & 13.204 & 1.973 & 58.985 & 74,27 \\
$1885-1886$ & 126.883 & 59.228 & 8.578 & 194.688 & 65,17 \\
1907 & 536.060 & 206.653 & 71.538 & 814.251 & 65,83 \\
\hline
\end{tabular}

Fonte: Gama (1823), Carreira (1889), Cavalcanti (1890) e Ipeadata (2013). *Nota: Valores em Contos de Réis.

**Nota: Valores interpolados.

De forma a obter valores mais representativos, nós interpolamos os valores indicados pelos autores acima com base na série de receita geral da união e 
encadeamos o resultado às séries de receita geral do setor público a partir de 1907 disponíveis no Ipeadata. Para consultar tais dados vide o apêndice estatístico. Os dados de exportações e importações de bens foram obtidos do site do Ipeadata. Os dados relativos à oferta de moeda M2, também disponíveis no Ipeadata, foram calculados por Pelaez \& Suzigan (1976) para o período de 1852 em diante. Para o período entre 1839 e 1851 existem dados de depósitos a vista e a prazo para o Banco do Brasil apenas, também de Pelaez \& Suzigan (1976) e para o período de 1810 a 1838 existem dados referentes apenas ao papel moeda emitido. Em vista disso, utilizamos o papel moeda emitido entre 1820 e 1838 e o M2 restrito (com depósitos a vista e a prazo apenas do Banco do Brasil) entre 1839 e 1851 representando o M2; e de 1852 em diante utilizamos o M2 de fato. Os resultados da regressão do log natural do PIB nominal entre 1900 e 1946 contra o log natural da população, da receita geral do setor público, das exportações e importações de bens e do conceito de moeda M2 (valores monetários em Contos de Réis) são mostrados na Tabela 3.

TABELA 3 - REGRESSÃO DE MQO DO LOG NATURAL DO PIB NOMINAL $1900 / 1946$

\begin{tabular}{|c|c|c|c|c|}
\hline & Coeficiente & $\begin{array}{c}\text { Erro } \\
\text { Padrão }\end{array}$ & Razão-t & P-valor \\
\hline $\begin{array}{l}\text { Ln Receitas do S. } \\
\text { Público }\end{array}$ & 0,209187 & 0,0620204 & 3,3729 & 0,00161 \\
\hline Ln Exportações & 0,258224 & 0,0710668 & 3,6335 & 0,00076 \\
\hline Ln Importações & 0,174815 & o,0572931 & 3,0512 & o,00394 \\
\hline Ln Moeda-M2 & 0,353583 & o,0495965 & 7,1292 & $<0,00001$ \\
\hline Ln População & o,105355 & o,0179814 & 5,8591 & $<0,00001$ \\
\hline \multicolumn{5}{|c|}{ Obs. 47 R2 = 0,9999 F(5,42) 598206 rô =-0,0108 Durbin-Watson = 2,02 } \\
\hline \multicolumn{5}{|c|}{ Diagnóstico dos resíduos e do modelo } \\
\hline Objeto do Teste & Teste & $\begin{array}{l}\text { Hipótese } \\
\text { Nula }\end{array}$ & $\begin{array}{l}\text { Est. do } \\
\text { Teste }\end{array}$ & p-valor \\
\hline Normalidade & $\begin{array}{l}\text { Jarque- } \\
\text {-Bera: } \\
\text { Qui2 (2) }\end{array}$ & $\begin{array}{l}\text { Os erros } \\
\text { são nor- } \\
\text { mais }\end{array}$ & 3,8844 & 0,1434 \\
\hline $\begin{array}{l}\text { Autocorrelação } 1^{\mathrm{a}} \\
\text { Ordem }\end{array}$ & $\begin{array}{l}\text { Durbin- } \\
\text {-Watson }\end{array}$ & $\begin{array}{l}\text { Sem auto- } \\
\text { correlação }\end{array}$ & 2,0200 & 0,3454 \\
\hline
\end{tabular}

Fonte: Elaboração própria a partir dos resultados obtidos do software econométrico Gretl 1.9.10.7

*Nota: O teste identificou três vetores de cointegração. 
TABELA 3 - REGRESSÃO DE MQO DO LOG NATURAL DO PIB NOMINAL 1900/1946 (CONTINUAÇÃO)

\begin{tabular}{|c|c|c|c|c|}
\hline \multicolumn{5}{|c|}{ Diagnóstico dos resíduos e do modelo } \\
\hline Objeto do Teste & Teste & $\begin{array}{l}\text { Hipótese } \\
\text { Nula }\end{array}$ & $\begin{array}{l}\text { Est. do } \\
\text { Teste }\end{array}$ & p-valor \\
\hline $\begin{array}{l}\text { Autocorrelação } 1^{\mathrm{a}} \\
\text { Ordem }\end{array}$ & $\begin{array}{l}\text { LM de } \\
\text { Breusch- } \\
\text { Godfrey }\end{array}$ & $\begin{array}{l}\text { Sem auto- } \\
\text { correlação }\end{array}$ & 0,0048 & 0,9449 \\
\hline $\begin{array}{l}\text { Autocorrelação } 2^{\mathrm{a}} \\
\text { Ordem }\end{array}$ & $\begin{array}{l}\text { LM de } \\
\text { Breusch- } \\
\text { Godfrey }\end{array}$ & $\begin{array}{l}\text { Sem auto- } \\
\text { correlação }\end{array}$ & 0,4566 & 0,6367 \\
\hline Heterocedasticidade & $\begin{array}{l}\text { LM de } \\
\text { White: } \\
\text { Qui2 (19) }\end{array}$ & $\begin{array}{l}\text { Sem Hete- } \\
\text { rocedastic. }\end{array}$ & 24,4503 & 0,1794 \\
\hline Heterocedasticidade & $\begin{array}{l}\text { LM de } \\
\text { Breusch- } \\
\text {-Pagan }\end{array}$ & $\begin{array}{l}\text { Sem Hete- } \\
\text { rocedastic. }\end{array}$ & 3,1476 & 0,5334 \\
\hline $\mathrm{ARCH} 1^{\mathrm{a}}$ ordem & LM & $\begin{array}{l}\text { Sem efeito } \\
\mathrm{ARCH}\end{array}$ & 0,0047 & 0,9451 \\
\hline $\mathrm{ARCH} 2^{\mathrm{a}}$ ordem & $\mathrm{LM}$ & $\begin{array}{l}\text { Sem efeito } \\
\text { ARCH }\end{array}$ & 0,0218 & 0,9891 \\
\hline $\begin{array}{l}\text { Estab. dos } \\
\text { parâmetros }\end{array}$ & CUSUM & $\begin{array}{l}\text { Parâm. } \\
\text { não mu- } \\
\text { dam }\end{array}$ & 0,1284 & 0,8985 \\
\hline
\end{tabular}

\begin{tabular}{|c|c|c|c|c|c|}
\hline \multicolumn{6}{|c|}{ Testes de Cointegração } \\
\hline Teste & Variante & Defasagens & $\begin{array}{c}\text { Hipótese } \\
\text { Nula }\end{array}$ & $\begin{array}{l}\text { Estatís. } \\
\text { do teste }\end{array}$ & p-valor \\
\hline Engle-Granger & $\begin{array}{l}\text { Sem } \\
\text { constante }\end{array}$ & $\mathrm{O}$ & $\begin{array}{l}\text { Sem } \\
\text { cointe- } \\
\text { gração }\end{array}$ & $-6,7860$ & 0,0001 \\
\hline Johansen/traço* & $\begin{array}{l}\text { Sem } \\
\text { constante }\end{array}$ & 3 & $\begin{array}{l}\text { Sem } \\
\text { cointe- } \\
\text { gração }\end{array}$ & 40,317 & 0,0474 \\
\hline
\end{tabular}

Fonte: Elaboracão própria a partir dos resultados obtidos do software econométrico Gretl 1.9.10.8

*Nota: O teste identificou três vetores de cointegração.

A regressão da Tabela 3 foi estimada em níveis não obstante a não- estacionariedade das variáveis envolvidas porque os testes de cointegração de Engle-Granger e de Johansen indicaram a presença de cointegração entre as 8 Disponível para download gratuito em: http://gretl.sourceforge.net/gretl_portugues.html 
variáveis. Portanto nossa estimativa do Log do PIB nominal para o período 1820-1899 foi feita de acordo com a seguinte equação:

$$
\operatorname{LnPIB}=0,2092 \operatorname{LnR}+0,2582 \operatorname{LnX}+0,1748 \operatorname{LnIM}+0,3536 \operatorname{LnM} 2+0,1054 \operatorname{LnPop}
$$

onde $L n P I B$ é o log natural do PIB nominal, $L n R$ é o log natural da receita total do setor público, $\operatorname{LnX}$ é o log natural das exportações de bens, LnIM é o log natural das importações de bens, $\operatorname{Ln} M 2$ é o log natural do estoque de moeda M2, e LnPop é o log natural da população residente.

O valor obtido pela equação ainda foi corrigido para outliers pelo programa TRAMO/SEATS do software GRETL 1.9.10. No Gráfico 1, mostramos as estimativas do PIB nominal deste trabalho, a de Goldsmith (1986) e a de Contador \& Haddad (1975) para efeitos de comparação. Uma inspeção visual do gráfico 1 mostra que os dados de Goldsmith superestimam os dados obtidos pelo nosso trabalho e por Contador \& Haddad (1975). Acreditamos que no caso de Goldsmith, os motivos para isso, além de ele ter usado uma média simples das variáveis, é que ele usou mais séries do que nós usamos em nossa estimativa como já dito antes.

GRÁFICO 1 - ESTIMATIVAS DO PIB NOMINAL: MILHARES DE CONTOS DE RÉIS - 1820/1900

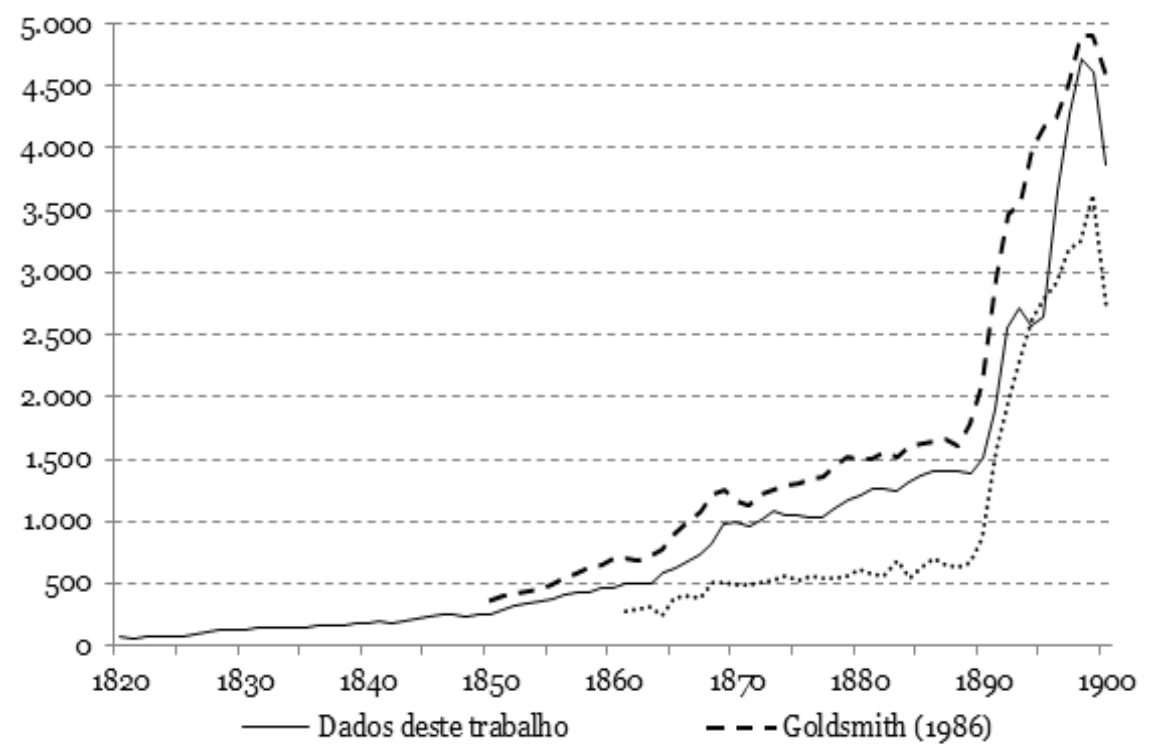

Fonte: Resultados do trabalho, Goldsmith (1986: 22-23, 82-83) e Contador \& Haddad (1975). 
A estimativa do PIB nominal para o ano de 1872 obtida na regressão acima foi de Rs 1.008.483:261 $\$ 776 ;{ }^{9}$ por seu lado, Reis (2008) num trabalho destinado a estimar a renda per capita brasileira em 1872 com base no censo demográfico nacional daquele ano, estimou o PIB (renda) nominal de 1872 em Rs 1.065.776:549\$000. Portanto nossa estimativa do PIB nominal em 1872 equivale a 94,62\% da estimativa de Reis (2008), a qual se utilizou de uma base de dados desagregada e nacionalmente mais abrangente. Isso, nós acreditamos, reforça a plausibilidade de nossas estimativas. ${ }^{10}$

\subsection{Estimação do deflator implícito do PIB}

Para obter uma estimativa do deflator implícito do PIB o procedimento foi semelhante ao que foi feito para calcular o PIB nominal. Utilizando índices de preços calculados para o século XIX e XX, foi feita uma regressão cointegrante do deflator implícito do PIB calculado entre 1889 e 1908 por Villela \& Suzigan (1973) e entre 1909 e 1947 por Haddad (1978) contra tais índices de preços. A regressão ajustada será utilizada para calcular uma estimativa do deflator implícito do PIB retroativamente até 1820. Os índices de preços para o século XIX geralmente são de preços ao consumidor calculados para uma região especifica como o de Lobo (1971) calculado para o Rio de Janeiro entre 1820 e 1930, ou são médias simples das variações de alguns preços como o índice de Onody (1960), Vieira (1947) e Buescu (1973). Outra abordagem comum para se estimar índices de preços para o século XIX é utilizar a Teoria da Paridade do Poder de Compra entre as taxas de câmbio. Tal abordagem foi utilizada por Leff (1991) e Luz \& Peláez (1972).

Este trabalho utilizou os índices de Lobo (1971) com ponderação de Affonseca Junior (1920), e Vieira (1947), além de elaborar um índice PPP nos moldes do que fizeram Leff (1991) e Luz \& Peláez (1972), utilizamos também um índice da taxa nominal de câmbio. O índice de Buescu (1973) não será utilizado porque cobre apenas o período 1826-1887. O índice de Leff (1991) não será utilizado porque cobre apenas o período 1822-1913 além de corrigir o índice PPP pelos termos de troca. A correção do índice PPP pelos termos de troca daria uma estimativa mais acurada do índice PPP; no entanto, não existem estimativas confiáveis de índices de preços para as exportações e importações para anos anteriores a 1850, o que acrescentaria mais incerteza ao índice PPP calculado. O índice de Luz \& Peláez (1972) não será utilizado porque os autores utilizam o preço ao consumidor do Reino Unido para calcular o índice, enquanto a teoria sugere um índice de preços no atacado. O índice PPP calculado neste trabalho utilizará o índice da taxa de cambio Mil-réis/

9 Rs é o símbolo da unidade monetária da época, o Mil-Réis que vigorou do período colonial até outubro de 1942 quando foi substituído pelo cruzeiro.

10 Além disso, nossas estimativas do PIB nominal para os anos de 1871 e 1873 foram de Rs 962.388:061\$933 e Rs 1.086.821:608 \$577 respectivamente, valores que também são próximos a estimativa para 1872 de Reis (2008). 
Libra Esterlina e o índice de preços no atacado no Reino Unido ${ }^{11}$ entre 1820 e 1930 de acordo com a seguinte fórmula:

$$
P P P_{B / R U}=I T x C_{R s / £ . I P A_{R U}}
$$

onde $P P P_{B / R U}$ é o índice de paridade do poder de compra do Brasil sobre o Reino Unido, $I T x C_{R s / £}$ é o índice da taxa de câmbio Mil-Réis/Libra Esterlina, e $I P A_{R U}$ é o índice de preços no atacado no Reino Unido. No gráfico 2, estão as séries dos índices de preços de Lobo (1971), Vieira (1947), e o índice PPP calculado acima.

GRÁFICO 2 - ÍNDICES DE PREÇOS DO SÉCULO XIX - LOGS, 1910=100 $1820 / 1930$

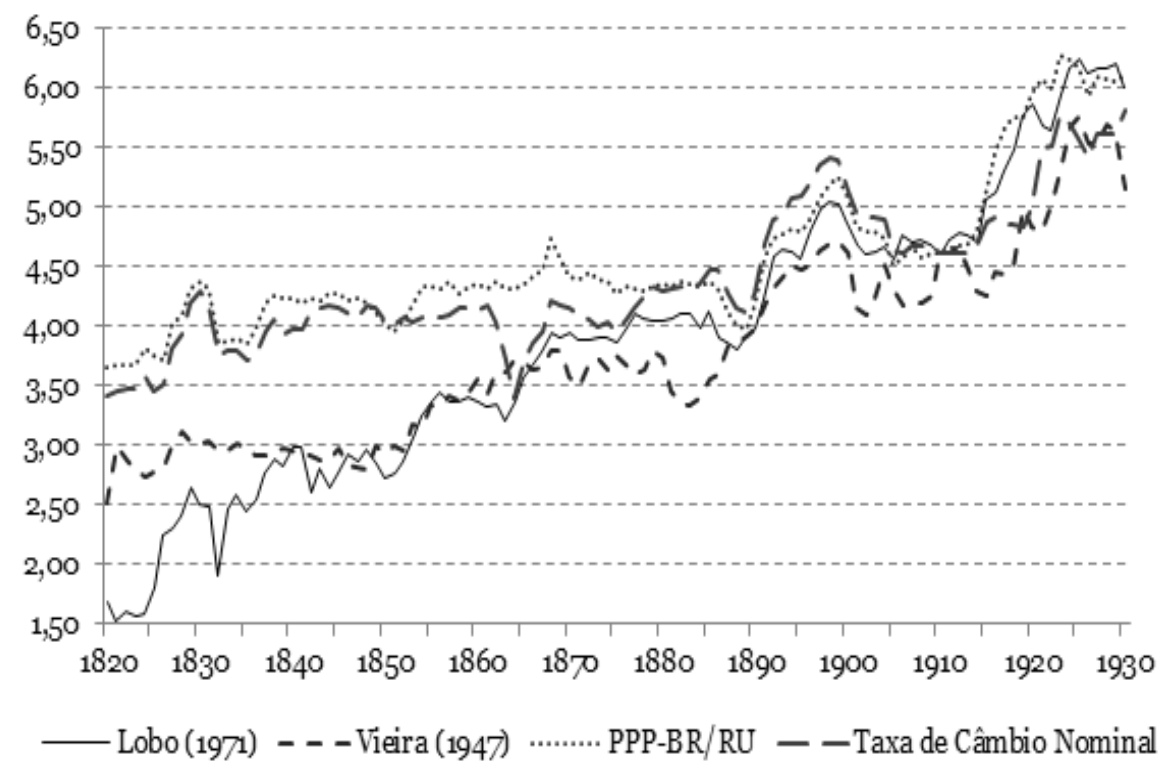

Fonte: Resultados do trabalho, Lobo (1971) e Vieira (1947).

Os quatro índices de preços mostrados no Gráfico 2 indicam que os preços foram crescentes no Brasil do século XIX, porém a inflação foi branda (para os padrões brasileiros), cerca de 1,91\% a.a. entre 1820 e 1889 , e 2,79\% a.a. entre 1820 e 1900 pela média dos índices de Lobo (1971), Vieira (1947) e do índice PPP construído acima. O resultado da regressão cointegrante do deflator implícito do PIB é mostrado na Tabela 4 abaixo. 
TABELA 4 - REGRESSÃO DE MQO DO LOG NATURAL DO DEFLATOR DO PIB $-1889 / 1930$

\begin{tabular}{lccccc}
\hline & Coeficiente & $\begin{array}{c}\text { Erro } \\
\text { Padrão }\end{array}$ & Razão-t & p-valor \\
\hline Constante & 1,219920 & 0,1297260 & 9,4038 & $<0,00001$ \\
Dummy 1889 & $-0,195367$ & 0,0673783 & $-2,8996$ & 0,00650 \\
Dummy 1890 & $-0,169363$ & 0,0664746 & $-2,5478$ & 0,01553 \\
Dummy 1889-1895 & $-0,120573$ & 0,0335120 & $-3,5979$ & 0,00101 \\
Ln Preços de Lobo (1971) & 0,514991 & 0,0961621 & 5,3554 & $<0,00001$ \\
Ln Preços de Vieira (1947) & 0,200174 & 0,0592410 & 3,3790 & 0,00184 \\
Ln Índice de Preços PPP & $-0,140906$ & 0,0764005 & $-1,8443$ & 0,07387 \\
Ln Índice Tx nom. de Câmbio & 0,149241 & 0,0503709 & 2,9628 & 0,00553
\end{tabular}

Obs. 42 R2 $=0,9857 \quad F(7,34)=335,8356$ rô $=0,07026$ Durbin-Watson $=1,86$

Diagnóstico dos resíduos e do modelo

\begin{tabular}{c|c|c|c|c}
\hline Objeto do Teste & Teste & $\begin{array}{c}\text { Hipótese } \\
\text { Nula }\end{array}$ & $\begin{array}{c}\text { Est. do } \\
\text { Teste }\end{array}$ & P-valor \\
\hline
\end{tabular}

Normalidade Jarque-Bera: Qui2 Os erros são (2) normais 5,4356 0,0660

AutocorrelaçãoDurbin$1^{\mathrm{a}}$ Ordem -Watson Sem autocor-

AutocorrelaçãoLM de $1^{\mathrm{a}}$ Ordem BreuschGodfrey

Sem autocorrelação

AutocorrelaçãoLM de $2^{\mathrm{a}}$ Ordem BreuschGodfrey

Sem autocorrelação 0,6825 0,5077 Heterocedasti-LM de cidade White: Qui2 Sem Hetero-
(20) 20,4289 0,4314 $0,5134 \quad 0,4753$

Heterocedasti-LM de cidade Breusch-Pagan Sem Heterocedastic. 5,7206 0,5727 $\mathrm{ARCH}$ LM: Qui2 Sem efeito $1^{\mathrm{a}}$ Ordem (1) $\mathrm{ARCH}$
0,2796

Fonte: Elaboração própria a partir dos resultados obtidos do software econométrico GNU Gretl 1.9.10.

*Nota: O teste identificou um vetor de cointegração. 
TABELA 4 - REGRESSÃO DE MQO DO LOG NATURAL DO DEFLATOR DO PIB - 1889/1930 (CONTINUAÇÃO)

Diagnóstico dos resíduos e do modelo

\begin{tabular}{|c|c|c|c|c|}
\hline Objeto do Teste & Teste & $\begin{array}{l}\text { Hipótese } \\
\text { Nula }\end{array}$ & $\begin{array}{l}\text { Est. do } \\
\text { Teste }\end{array}$ & P-valor \\
\hline $\begin{array}{l}\text { ARCH } \\
2^{\mathrm{a}} \text { Ordem }\end{array}$ & $\begin{array}{l}\text { LM: Qui2 } \\
\text { (2) }\end{array}$ & $\begin{array}{l}\text { Sem efeito } \\
\text { ARCH }\end{array}$ & 0,9800 & 0,6126 \\
\hline $\begin{array}{l}\text { Estab. dos } \\
\text { parâmetros. }\end{array}$ & CUSUM & $\begin{array}{l}\text { Parâm. não } \\
\text { mudam }\end{array}$ & $-1,5803$ & 0,1236 \\
\hline
\end{tabular}

Testes de Cointegração

\begin{tabular}{ll|c|c|c|c}
\hline \multicolumn{1}{c|}{ Teste } & Variante & Defasagens & $\begin{array}{c}\text { Hipótese } \\
\text { Nula }\end{array}$ & $\begin{array}{c}\text { Est. } \\
\text { do teste }\end{array}$ & p-valor \\
\hline Engle-Granger & $\begin{array}{l}\text { Com } \\
\text { constante }\end{array}$ & 0 & $\begin{array}{l}\text { Sem cointe- } \\
\text { gração }\end{array}$ & $-5,8948$ & 0,0422 \\
$\begin{array}{l}\text { Johansen/ } \\
\text { traço* }\end{array}$ & $\begin{array}{l}\text { Com } \\
\text { constante }\end{array}$ & 2 & $\begin{array}{l}\text { Sem cointe- } \\
\text { gração }\end{array}$ & 55,891 & 0,0326 \\
\hline
\end{tabular}

Fonte: Elaboração própria a partir dos resultados obtidos do software econométrico GNU Gretl 1.9.10.

*Nota: O teste identificou um vetor de cointegração.

A regressão da Tabela 4 foi estimada em níveis não obstante a não- estacionariedade das variáveis envolvidas, porque os testes de cointegração de Engle-Granger e também de Johansen indicaram a presença de cointegração entre as variáveis. Além disso, quando da presença de observações atípicas, foram incluídas variáveis dummies de forma a tornar a distribuição dos resíduos normal. Portanto nossa estimativa do Log do PIB nominal para o período 1820-1899 foi feita de acordo com a seguinte equação:

$$
\text { LnDef }=1,22+0,525 \text { LnLobo }+0,20 \text { LnVieira }-0,1409 \operatorname{LnPPP}+0,1492 \operatorname{LnTxC}
$$

onde LnDef é o log natural do deflator do PIB, LnLobo é o log natural do índice de preços de Lobo (1971), LnVieira é o log natural do índice de preços de Vieira (1947), LnPPP é o log natural do índice de preços de paridade do poder de compra, e $\operatorname{LnTxC}$ é o log natural do índice da taxa de câmbio nominal Mil-Réis/Libra.

No Gráfico 3, mostramos o Deflator do PIB calculado neste trabalho encadeado ao índice de Villela \& Suzigan (1973) e o calculado por Goldsmith (1986) para efeitos de comparação. Uma inspeção simples do gráfico mostra que o índice de Goldsmith é bem semelhante ao nosso no período 1850-1888, e sobre-estima o índice de Villela \& Suzigan (1973) para o período 1889-1897, voltando a ser praticamente igual no período 1898-1913. 
GRÁFICO 3 - DEFLATORES DO PIB - LOGARITMOS: 1910=100 - 1820/1913

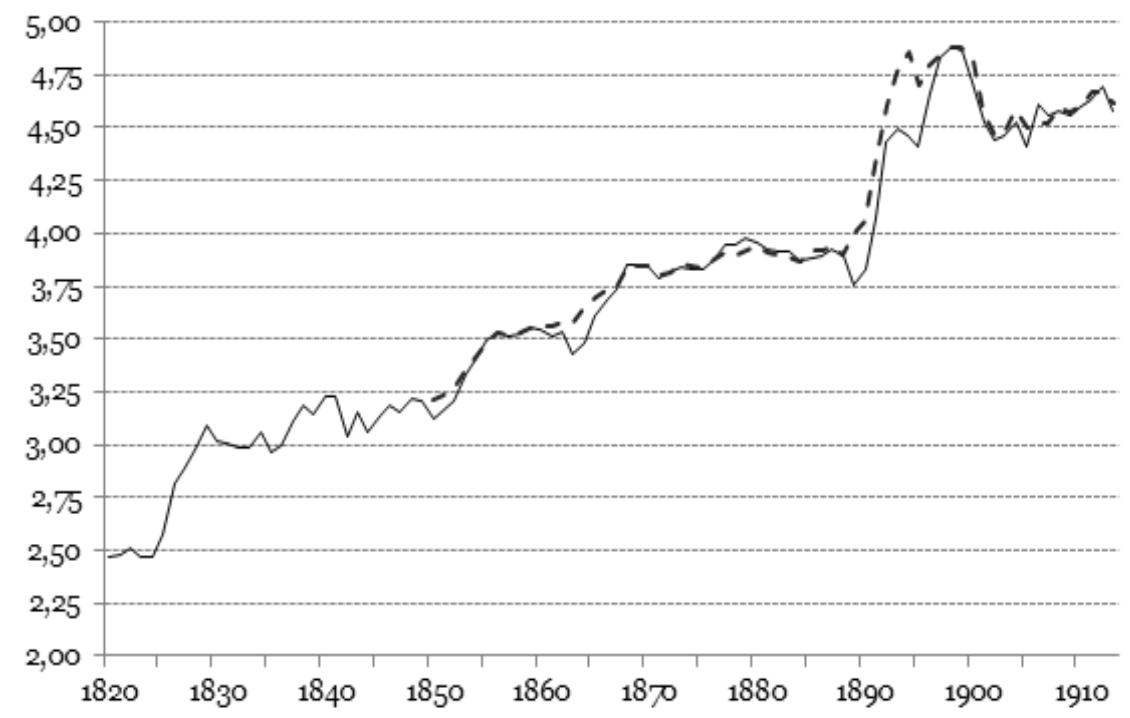

— Deflator calculado neste trabalho - - - Deflator calculado por Goldsmith (1986)

Fonte:Resultados do trabalho e Goldsmith (1986: 22-23, 82-83).

\subsection{O PIB real no período 1820-1900}

Na Tabela 5 nós mostramos algumas estimativas de outros autores comparadas com as nossas para o crescimento do PIB real entre 1850 e 1913. A grosso modo, as estimativas são semelhantes no que diz respeito a movimentos de tendência, isto, aumentam e diminuem ao mesmo tempo em praticamente todas as observações da tabela. No Gráfico 4 são mostrados o PIB real estimado neste trabalho e o estimado por Goldsmith (1986) e Contador \& Haddad (1975). A inspeção do Gráfico 4 revela que a estimativa de Goldsmith sobre-estima os valores por nós calculados neste trabalho e também os calculados por Contador \& Haddad (1975).

Um exercício interessante como sugerido por Contador \& Haddad (1975: 413) é tentar identificar na série de PIB real estimada perturbações causadas por fatos e eventos históricos. Tal exercício é ilustrado na Figura 1. Depois da independência em 1822, o Brasil entrou em guerra entre 1825 e 1828 contra Argentina pela posse da então província brasileira da Cisplatina, o conflito terminou em acordo no ano de 1828 com a independência da região sob o nome de República Oriental do Uruguai. 
TABELA 5 - ESTIMATIVAS ALTERNATIVAS DE CRESCIMENTO DO PIB: EM \% A.A. $-1850 / 1910 *$

\begin{tabular}{c|c|c|c|c|c|c|c}
\hline \multirow{2}{*}{ Período } & \multirow{2}{*}{ Pop. } & \multicolumn{2}{c|}{$\begin{array}{c}\text { Contador e } \\
\text { Haddad }\end{array}$} & \multicolumn{2}{c|}{ Goldsmith } & \multicolumn{2}{c}{ Este trabalho } \\
\cline { 2 - 8 } & & Agreg. & Per cap. & Agreg. & Per cap. & Agreg. & Per cap. \\
\cline { 2 - 8 } & A & B & - B - A & C & = - A & D & = D - A \\
\hline $1850-1860$ & 1,53 & - & - & 2,59 & 1,06 & 2,39 & 0,85 \\
$1860-1870$ & 1,47 & 2,97 & 1,50 & 3,09 & 1,62 & 3,69 & 2,22 \\
$1870-1880$ & 1,90 & 1,83 & $-0,07$ & 1,60 & $-0,30$ & 1,68 & $-0,22$ \\
$1880-1890$ & 1,97 & 1,56 & $-0,41$ & 1,17 & $-0,80$ & 2,49 & 0,52 \\
$1890-1900$ & 1,98 & 0,16 & $-1,82$ & 1,51 & $-0,47$ & 1,93 & $-0,05$ \\
$1900-1910$ & 3,00 & 7,84 & 4,84 & 3,81 & 0,81 & 3,51 & 0,51 \\
$1850-1900$ & 1,77 & - & - & 1,99 & 0,22 & 2,43 & 0,66 \\
$1860-1900$ & 1,83 & 1,55 & $-0,28$ & 1,84 & 0,01 & 2,44 & 0,61 \\
$1850-1910$ & 1,97 & - & - & 2,29 & 0,32 & 2,61 & 0,64 \\
$1860-1910$ & 2,06 & 2,78 & 0,72 & 2,23 & 0,17 & 2,66 & 0,59 \\
\hline
\end{tabular}

Fonte: Resultados do trabalho, Contador \& Haddad (1975) e Goldsmith (1986).

* Nota: Valores calculados a partir da tendência das séries calculadas pelo Filtro HP $\operatorname{com} \lambda=100$.

O período de entre 1835 e 1845 foi marcado por várias revoltas regionais como a Revolta dos Malês (1835) em Salvador-Bahia, a Revolta de Cabanagem (1835-1840) no Pará, a Revolta Farroupilha (1835-1845) no Rio Grande do Sul, a Revolta Sabinada (1837-1838) na Bahia, a Revolta de Balaiada (18381841) no Maranhão, e as Revoltas Liberais (1842) de Minas Gerais e São Paulo. Entre 1848 e 1850 ocorreu a última rebelião interna do Império, esta ocorreu no Pará e chamou-se de Revolta Praieira. Em 1864, o Brasil lutou contra o ditador uruguaio Aguirre e no mesmo ano entrou em guerra contra o Paraguai numa aliança com Argentina e Uruguai sendo que esta guerra durou até 1870. Também em 1864 ocorreu uma grande crise comercial e bancária no Rio de Janeiro. É sabido também que entre 1875 e 1880 o nordeste brasileiro enfrentou uma seca devastadora, tal período também foi marcado por uma recessão mundial. 
GRÁFICO 4 - ESTIMATIVAS DO PIB REAL: MILHARES DE CONTOS DE RÉIS DE $1910-1820 / 1900$

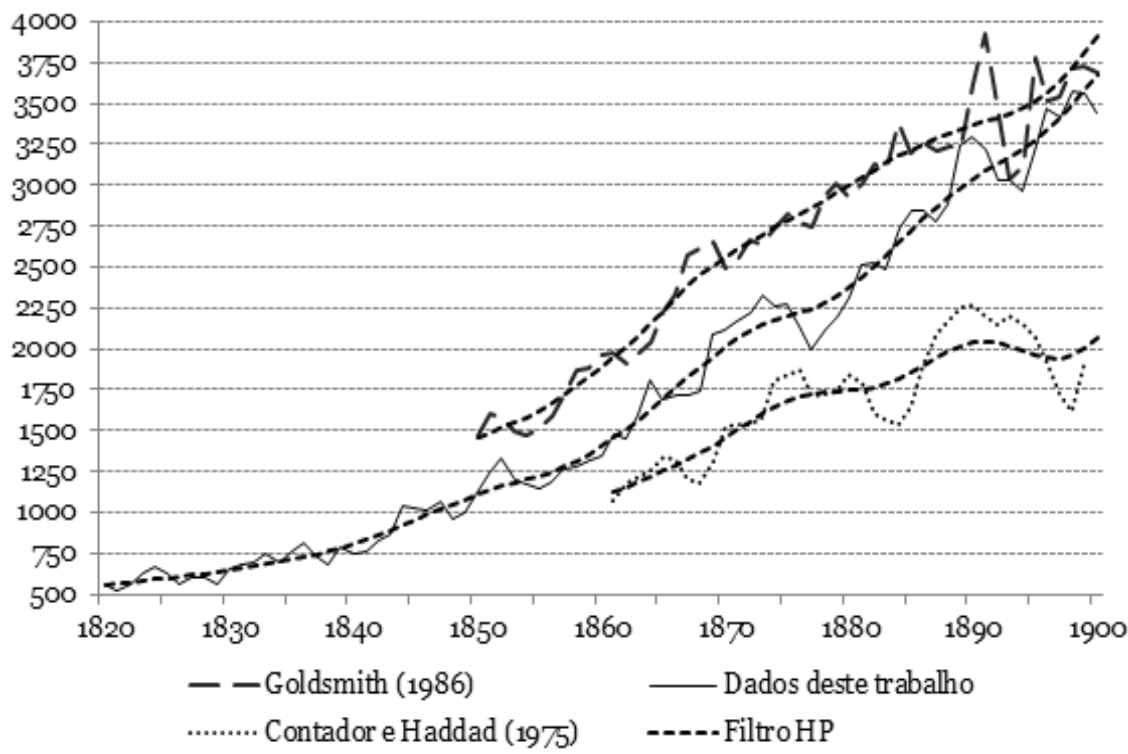

Fonte: Resultados do trabalho, Goldsmith (1986) e Contador \& Haddad (1975).

FIGURA 1 - PIB REAL EM BILHÕES DE REAIS DE 2008 E FATOS HISTÓRICOS $-1820 / 1900$

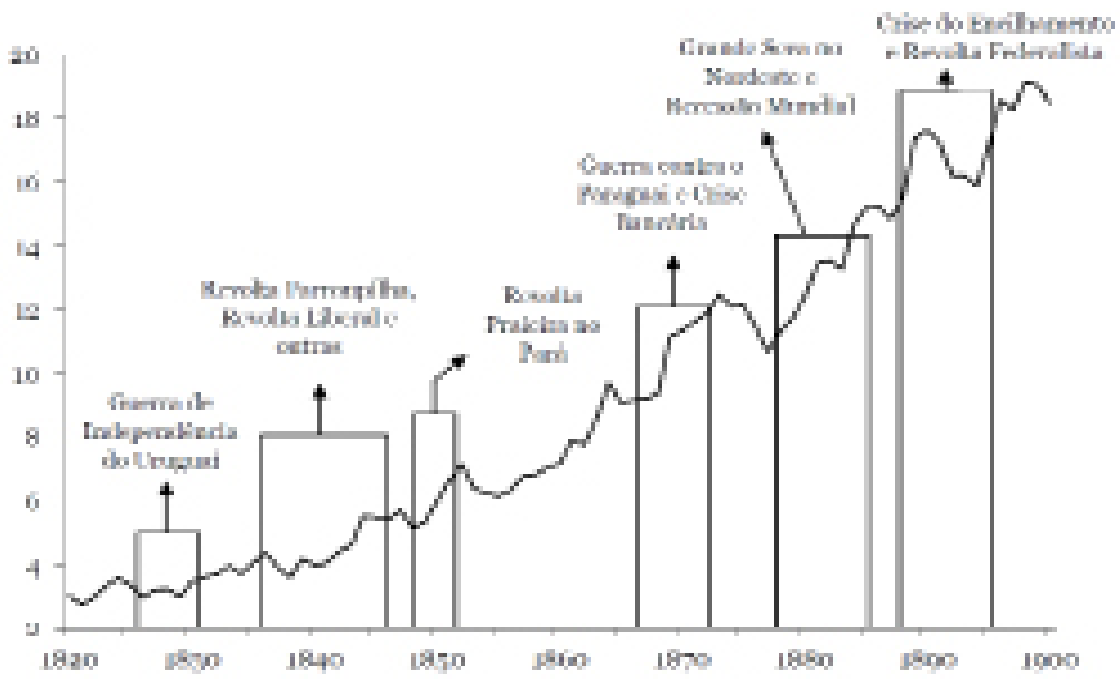

Fonte: Elaboração própria a partir dos resultados do trabalho. 
Em 1888 foi criada uma lei autorizando a emissão de moeda por bancos particulares. A oferta de moeda teria crescido mais de $100 \%$ entre 1888 e 1894. Em 1892 começaram as falências e concordatas no que ficou conhecido como a crise do encilhamento. (CONTADOR e HADDAD, 1975). Entre 1893 e 1897 ocorreram as primeiras revoltas do período republicano que foram a Revolta da Armada (1893-1894) no Rio de Janeiro, a Revolta Federalista (1893-1895) no sul e sudeste do Brasil, e a Guerra de Canudos (1893-1897) no interior da Bahia. Outros eventos históricos importantes nessa época foram a abolição da escravidão em maio de 1888 e a proclamação da república em novembro de 1889.

Na Tabela 6 nós mostramos relações da economia brasileira do século XIX e início do XX tais como velocidades de circulação dos agregados monetários, participação das exportações, importações e receita geral do setor público no PIB. A velocidade de circulação dos agregados monetários permaneceu praticamente constante durante o século XIX com leve movimento ascendente no final do século XIX e início do XX. A participação das exportações no PIB registrou tendência de queda durante o período. Na década de 1820 essa participação era de $26 \%$, na década de 1920 havia caído para 14,59\%. A participação das importações no PIB também mostrou tendência de queda no período. Na década de 1820 essa participação era de $28 \%$, na década de 1920 havia caído para $12,54 \%$.

TABELA 6 - COMPORTAMENTO DAS VELOCIDADES DE CIRCULAÇÃO, DO COMÉRCIO EXTERIOR E DA CARGA TRIBUTÁRIA - 1820/1920

\begin{tabular}{|c|c|c|c|c|c|c|c|}
\hline & $\mathrm{V}_{\mathrm{pm}}$ & Vo & $\mathrm{V} 1$ & $\mathrm{~V} 2$ & $\mathrm{X} / \mathrm{PIB}$ & IM/PIB & $\mathrm{R}_{\mathrm{sp}} / \mathrm{PIB}$ \\
\hline 1820 & 6,76 & - & - & - & 26,09 & 28,07 & 18,14 \\
\hline 1830 & 4,91 & - & - & - & 22,38 & 24,60 & 13,91 \\
\hline 1840 & 4,66 & - & - & - & 21,70 & 24,78 & 12,33 \\
\hline 1850 & 5,41 & 5,99 & 5,50 & 4,58 & 22,84 & 26,08 & 13,76 \\
\hline 1860 & 5,67 & 6,55 & 5,04 & 4,55 & 23,18 & 20,88 & 13,46 \\
\hline 1870 & 5,47 & 5,83 & 4,59 & 3,99 & 18,52 & 15,56 & 15,11 \\
\hline 1880 & 6,43 & 7,51 & 5,37 & 4,10 & 17,45 & 14,34 & 16,23 \\
\hline 1890 & 4,82 & 6,85 & 3,87 & 3,15 & 22,47 & 20,18 & 14,67 \\
\hline 1900 & 5,64 & 7,10 & 5,18 & 4,77 & 20,20 & 13,10 & 15,91 \\
\hline 1910 & 5,79 & 7,95 & 4,70 & 3,89 & 16,67 & 12,61 & 14,14 \\
\hline 1920 & 7,98 & 11,66 & 4,86 & 3,89 & 14,59 & 12,54 & 12,33 \\
\hline Média & 5,78 & 7,43 & 4,89 & 4,11 & 20,55 & 19,34 & 14,54 \\
\hline
\end{tabular}

Fonte: Elaboração própria.

Nota: Vpm, Vo, V1 e V2 são as velocidades do papel moeda emitido, de Mo, de M1 e de M2; X representa as exportações, IM as importações e Rsp é a receita total do setor público. Todos estão como razão do PIB nominal. 
A receita total do setor público, uma proxy para a carga tributária ${ }^{12}$, oscilou entre 13 e 16\% do PIB no período entre 1820 e 1920, isto é, era cerca da metade do que é hoje. Na Tabela 7 mostramos a evolução do PIB real total e per capita em reais de 2008. O PIB real total aumentou 1104 vezes em 192 anos, o que dá uma taxa de crescimento anual média de 3,74 \% a.a. O PIB real per capita, por sua vez, aumentou 27 vezes em 192 anos, o que dá uma taxa de crescimento anual média de 1,74\% a.a.

TABELA 7 - PIB REAL TOTAL EM MILHÕES E PER CAPITA EM REAIS (R\$ DE 2008) - 1820/2011

\begin{tabular}{cccccccc}
\hline Ano & PIB & PIB per capita & Ano & PIB & PIB per capita \\
\hline 1820 & 3.025 & 641 & 1890 & 17.657 & 1.232 \\
1830 & 3.502 & 654 & 1900 & 18.481 & 1.060 \\
1840 & 4.000 & 642 & 1925 & 51.256 & 1.535 \\
1850 & 6.033 & 831 & 1950 & 179.593 & 3.457 \\
1860 & 7.188 & 851 & 1975 & 1.076 .533 & 10.141 \\
1870 & 11.368 & 1.163 & 2000 & 2.278 .662 & 13.304 \\
1880 & 12.427 & 1.053 & 2011 & 3.338 .702 & 17.355 \\
\hline
\end{tabular}

Fonte: Elaboração própria a partir dos resultados do trabalho.

\section{Comparações Internacionais}

A fim de comparar os nossos dados com os de Maddison (2006) é necessário que nossa estimativa do PIB possa ser convertida em dólares internacionais de Geary-Khamis de 2008. Para obter uma estimativa de tal conversão, nós estimamos uma regressão cointegrante para o período 1900-1946 do log do PIB brasileiro, medido em dólares internacionais de 2008, contra o log do PIB brasileiro em reais de 2008, o log do deflator implícito do PIB, e o log do índice de preços ao consumidor (CPI) dos Estados Unidos. Os resultados da regressão estimada são mostrados na Tabela 8.

Os testes de Durbin-Watson e o teste LM de Breusch-Godfrey identificaram a presença de autocorrelação de primeira ordem a pelo menos 5\% de significância na regressão da Tabela 8. O teste LM de White identificou heterocedasticidade a 5\% de significância e o teste LM de Breusch-Pagan a identificou a 10\% de significância. Em vista disso a regressão da tabela 8 foi reestimada por máxima verossimilhança para corrigir a autocorrelação de primeira ordem dos resíduos. $\mathrm{O}$ resultado dessa estimação também está na Tabela 8 . $\mathrm{O}$ PIB em dólares internacionais de 2008 estimado na regressão da tabela 8 é mostrado no Gráfico 5 juntamente com a estimativa de Maddison (2006). 12 Essa receita total do setor público inclui outros tipos de receitas como empréstimos, emissões de moeda, venda de ativos, receitas de empresas estatais, etc. 
As estimativas de Maddison são continuas, isto é, disponíveis ano a ano entre 1870 e 2008. Para o período anterior a 1870 existem estimativas apenas para 1820 e 1850. A fim de se obter uma melhor visualização do gráfico, nós interpolamos os dados de Maddison no Gráfico 5.

TABELA 8 - REGRESSÃO DE MQO DO LOG NATURAL DO PIB EM DÓLARES DE GEARY-KHAMIS DE 2008 - 1900/1946

\begin{tabular}{|c|c|c|c|c|}
\hline & Coeficiente & Erro Padrão & Razão-t & p-valor \\
\hline Constante & 1,4088600 & o,0728379 & 19,3425 & $<0,00001$ \\
\hline Dummy em 1911 & o,0574719 & 0,0154243 & 3,7261 & 0,00060 \\
\hline Dummy em 1930 & $-0,0482869$ & o,0153946 & $-3,1366$ & 0,00320 \\
\hline Dummy em 1943 & 0,04469860 & 0,0156855 & 2,8497 & 0,00688 \\
\hline Ln PIB R\$ de 2008 & 0,7851580 & 0,010046 & 78,1561 & $<0,00001$ \\
\hline Ln Deflator do PIB & 0,0406152 & 0,0134131 & 3,0280 & 0,00430 \\
\hline Ln CPI dos EUA & o,11331500 & 0,0145812 & 7,7713 & $<0,00001$ \\
\hline \multicolumn{5}{|c|}{ Obs. $47 \mathrm{R} 2=0,9992 \mathrm{~F}(6,40)=8737,6$ rô $=0,3204$ Durbin-Watson $=1,36$} \\
\hline \multicolumn{5}{|c|}{ Diagnóstico dos resíduos e do modelo } \\
\hline Objeto do Teste & Teste & Hipótese Nula & $\begin{array}{c}\text { Est. do } \\
\text { Teste } \\
\end{array}$ & p-valor \\
\hline Normalidade & $\begin{array}{l}\text { Jarque-Bera: } \\
\text { Qui2 (2) }\end{array}$ & $\begin{array}{l}\text { Os erros são } \\
\text { normais }\end{array}$ & 1,0608 & 0,5884 \\
\hline $\begin{array}{l}\text { Autocorrelação } \\
1^{\text {a }} \text { Ordem }\end{array}$ & $\begin{array}{l}\text { Durbin-Wat- } \\
\text { son }\end{array}$ & $\begin{array}{l}\text { Sem autocor- } \\
\text { relação }\end{array}$ & 1,3552 & 0,0028 \\
\hline $\begin{array}{l}\text { Autocorrelação } \\
1^{\mathrm{a}} \text { Ordem }\end{array}$ & $\begin{array}{l}\text { LM de Breus- } \\
\text { ch- Godfrey }\end{array}$ & $\begin{array}{l}\text { Sem autocor- } \\
\text { relação }\end{array}$ & 4,8073 & 0,0343 \\
\hline $\begin{array}{l}\text { Autocorrelação } \\
2^{\circ} \text { Ordem }\end{array}$ & $\begin{array}{l}\text { LM de Breus- } \\
\text { ch- Godfrey }\end{array}$ & $\begin{array}{l}\text { Sem autocor- } \\
\text { relação }\end{array}$ & 2,5590 & 0,0907 \\
\hline $\begin{array}{l}\text { Heterocedastici- } \\
\text { dade }\end{array}$ & $\begin{array}{l}\text { LM de White: } \\
\text { Qui2 (12) }\end{array}$ & $\begin{array}{l}\text { Sem Heteroce- } \\
\text { dastic. }\end{array}$ & 21,348 & 0,0455 \\
\hline $\begin{array}{l}\text { Heterocedastici- } \\
\text { dade }\end{array}$ & $\begin{array}{l}\text { LM de Breus- } \\
\text { ch-Pagan }\end{array}$ & $\begin{array}{l}\text { Sem Heteroce- } \\
\text { dastic. }\end{array}$ & 12,341 & 0,0548 \\
\hline ARCH $1^{\mathrm{a}}$ Ordem & LM: Qui2 (1) & $\begin{array}{l}\text { Sem efeito } \\
\text { ARCH }\end{array}$ & 1,2374 & 0,2660 \\
\hline ARCH $2^{\mathrm{a}}$ Ordem & LM: Qui2 (2) & $\begin{array}{l}\text { Sem efeito } \\
\text { ARCH }\end{array}$ & 1,7443 & 0,4180 \\
\hline $\begin{array}{l}\text { Estabilidade dos } \\
\text { parâmetros }\end{array}$ & CUSUM & $\begin{array}{l}\text { Parâmetros } \\
\text { não mudam }\end{array}$ & 1,1868 & 0,2425 \\
\hline
\end{tabular}

Fonte: Resultados do trabalho a partir do software econométrico GNU GRETL 1.9.10. 
TABELA 8 - REGRESSÃO DE MQO DO LOG NATURAL DO PIB EM DÓLARES DE GEARY-KHAMIS DE 2008 - 1900/1946

\begin{tabular}{|c|c|c|c|c|c|}
\hline Teste & Variante & Defasagens & $\begin{array}{l}\text { Hipótese } \\
\text { Nula }\end{array}$ & $\begin{array}{c}\text { Est. do } \\
\text { teste }\end{array}$ & p-valor \\
\hline \multicolumn{2}{|c|}{ Engle-Granger Com constante } & o & $\begin{array}{l}\text { Sem } \\
\text { cointegração }\end{array}$ & $-5,2330$ & 0,0064 \\
\hline $\begin{array}{l}\text { Johansen/ } \\
\text { traço }\end{array}$ & Com constante & 2 & $\begin{array}{l}\text { Sem } \\
\text { cointegração }\end{array}$ & 44,678 & 0,0029 \\
\hline \multicolumn{6}{|c|}{ Estimativa em Máxima Verossimilhança com Média Móvel de uma Defasagem } \\
\hline & Coeficiente & Erro Padrão & $\mathrm{Z}$ & \multicolumn{2}{|c|}{ p-valor } \\
\hline Constante & 1,4105300 & 0,0806924 & 17,4803 & \multicolumn{2}{|c|}{$<0,00001$} \\
\hline MA (1) & 0,4313320 & 0,1405360 & 3,06920 & \multicolumn{2}{|c|}{0,002150} \\
\hline $\begin{array}{l}\text { Dummy de } \\
1911\end{array}$ & 0,0644326 & o,0120128 & 5,36360 & \multicolumn{2}{|c|}{$<0,00001$} \\
\hline $\begin{array}{l}\text { Dummy de } \\
1930\end{array}$ & $-0,0325119$ & o,0125703 & $-2,58640$ & \multicolumn{2}{|c|}{ o,009700 } \\
\hline $\begin{array}{l}\text { Dummy } \\
\text { de1943 }\end{array}$ & o,0473983 & 0,0118854 & 3,98800 & \multicolumn{2}{|c|}{0,000070} \\
\hline $\begin{array}{l}\text { Ln PIB R } \$ \text { de } \\
2008\end{array}$ & 0,7876630 & o,0113639 & 69,3129 & \multicolumn{2}{|c|}{$<0,00001$} \\
\hline $\begin{array}{l}\text { LnDeflator do } \\
\text { PIB }\end{array}$ & 0,0402465 & 0,0144005 & 2,79480 & \multicolumn{2}{|c|}{ 0,005190 } \\
\hline $\begin{array}{l}\text { Ln CPI dos } \\
\text { EUA }\end{array}$ & o,1077910 & 0,0169484 & 6,35990 & \multicolumn{2}{|c|}{$<0,00001$} \\
\hline
\end{tabular}

Fonte: Resultados do trabalho a partir do software econométrico GNU GRETL 1.9.10.

A visualização do Gráfico 5 mostra que as duas séries tem uma tendência comum e muito próxima, indicando que as nossas estimativas estão bem próximas das de Maddison (2006) para o século XIX com a vantagem de que as nossas estão disponíveis ano a ano de forma contínua. Na tabela 9 mostramos uma comparação entre as nossas estimativas do PIB brasileiro em dólares internacionais de 2008 com as de Maddison (2006). Novamente constata-se que os valores são bem próximos como sugerido no Gráfico 5 . 
GRÁFICO 5 - ESTIMATIVAS DO PIB REAL EM BILHÕES DE DÓLARES INTERNACIONAIS DE GEARY-KHAMIS - 1820/1900

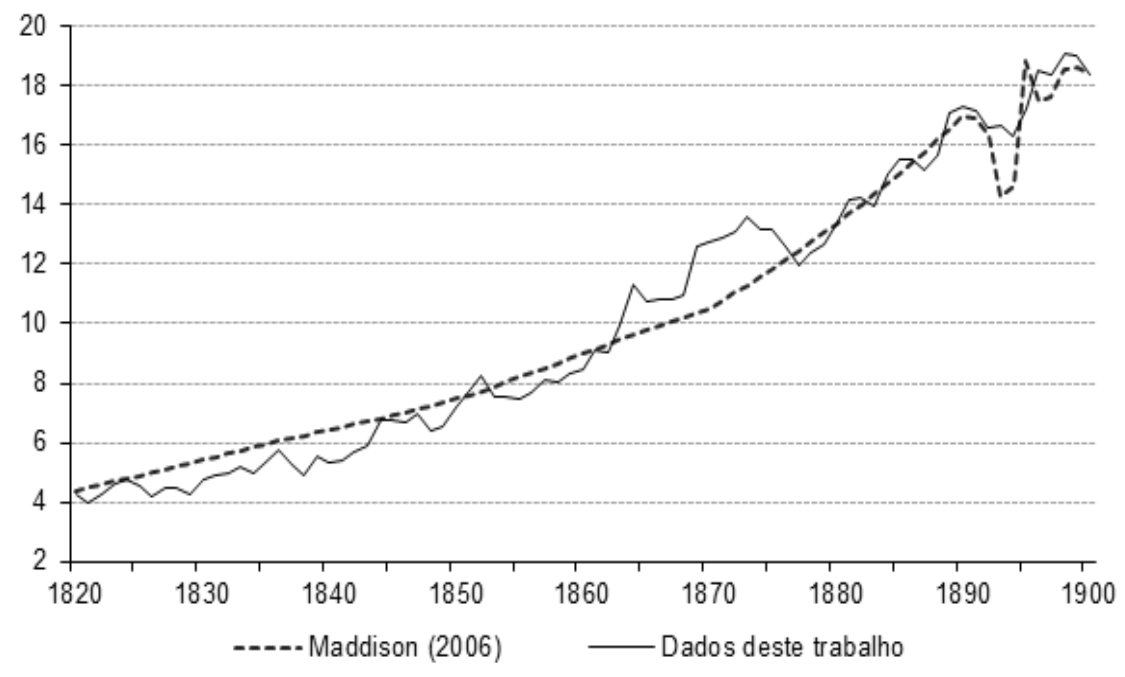

Fonte: Resultados do trabalho e Maddison (2006).

TABELA 9 - PIB BRASILEIRO EM MILHÕES DE DÓLARES DE GEARY-KHAMIS DE $2008-1820 / 1890$

\begin{tabular}{l|c|c|c|c|c|c|c|c}
\hline \multirow{2}{*}{} & \multicolumn{2}{|c|}{ PIB } & \multicolumn{2}{c|}{ PIB per capita } & \multicolumn{2}{c|}{$\begin{array}{c}\text { Taxa de cresc. PIB } \\
\% \text { a.a. }\end{array}$} & \multicolumn{2}{c}{$\begin{array}{c}\text { Taxa cresc. } \\
\text { PIB pc \% a.a. }\end{array}$} \\
\cline { 2 - 9 } & Maddison & $\begin{array}{c}\text { Este } \\
\text { Trabalho }\end{array}$ & Maddison & $\begin{array}{c}\text { Este } \\
\text { Trabalho }\end{array}$ & Maddison & $\begin{array}{c}\text { Este } \\
\text { Trabalho }\end{array}$ & Maddison & $\begin{array}{c}\text { Este } \\
\text { Trabalho }\end{array}$ \\
\hline 1820 & 4.387 & 4.284 & 930 & 908 & - & - & - & - \\
1850 & 7.472 & 7.166 & 1.030 & 988 & 1,79 & 1,73 & 0,34 & 0,28 \\
1870 & 10.525 & 12.711 & 1.077 & 1.300 & 1,73 & 2,91 & 0,22 & 1,38 \\
1880 & 13.366 & 13.305 & 1.133 & 1.128 & 2,42 & 0,46 & 0,51 & $-1,41$ \\
1890 & 16.976 & 17.317 & 1.184 & 1.208 & 2,42 & 2,67 & 0,45 & 0,69 \\
\hline
\end{tabular}

Fonte: Maddison (2006) e resultados do trabalho.

A observação do Gráfico 6 revela que a renda per capita brasileira como razão da renda per capita norte-americana diminuiu sistematicamente entre 1820 e 1918. Em 1820 o Brasil tinha uma renda per capita equivalente a $48 \%$ da renda per capita norte-americana, em 1918 esse número era de 12,79\% apenas. Entre 1919 e 1980 a renda per capita brasileira aumentou como proporção da renda per capita norte-americana. Em 1919 o Brasil tinha uma renda per capita equivalente a 14,49\% da renda per capita norte-americana, em 1980 o 
número era de 29,02\%, a maior proporção entre a renda per capita brasileira e a norte-americana depois do ano de 1876 . Entre 1981 e 2011 a razão voltou a diminuir se estabilizando por volta de $20 \%$ em 2008.
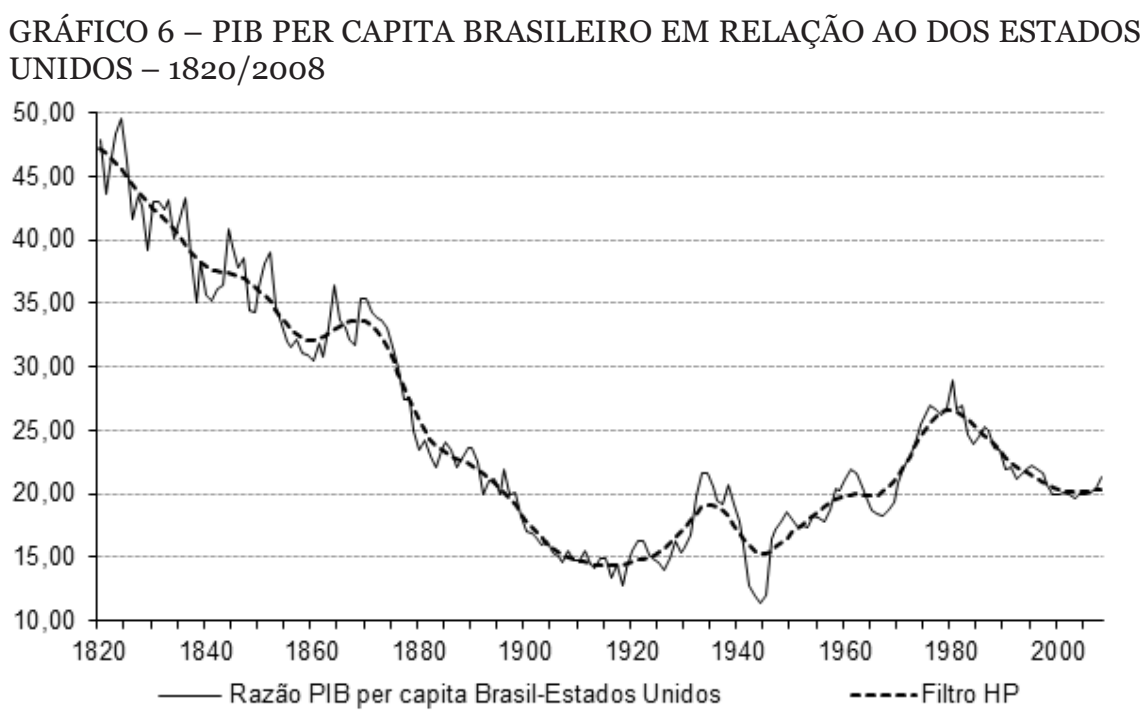

Fonte: Resultados do trabalho para o Brasil e Maddison (2006) para os EUA.

Em dólares internacionais a renda per capita brasileira cresceu de $\mathrm{I} \$ 908^{13} \mathrm{em}$ 1820 a I\$ 10.030 em 2008, implicando uma taxa anual média de crescimento da renda per capita em torno de 1,29\% a.a. Os Estados Unidos, por sua vez, tiveram uma taxa anual média de crescimento da renda per capita em torno de $1,72 \%$ a.a. A diferença de apenas 0,43 pontos percentuais entre as duas taxas mostra como as taxas compostas podem produzir grandes diferenças em intervalos suficientemente longos de tempo. Essa diferença nas taxas fez com que a renda per capita brasileira que era cerca de 50\% da norte-americana em 1820 caísse para cerca de $20 \%$ em 2008.

Se o Brasil tivesse uma renda per capita igual à norte-americana em 1820, então com uma taxa de crescimento média de 1,29\% a.a. o Brasil teria em 2008 uma renda per capita de I\$ 21.081 , ou seja, equivalente a $44,88 \%$ da norte-americana ou quase igual a do Chile. Por outro lado, se com a renda inicial de I\$ 908 em 1820 o Brasil tivesse tido uma taxa de crescimento anual da renda per capita igual a dos Estados Unidos entre 1820 e 2008, isto é, $1,72 \%$ a.a., a renda per capita do país estaria hoje em torno de I\$ 22.412, ou equivalente a $48 \%$ da norte-americana. Na tabela 10 nós mostramos a renda 
per capita entre 1820 e 2011 para oito países selecionados inclusive o Brasil.

A análise desses dados mostra como diferenças de crescimento da renda que parecem pequenas no curto prazo podem produzir grandes disparidades no longo prazo. Portanto, em termos da análise da série temporal do PIB apenas, a atual baixa renda per capita brasileira depende em parte do baixo nível da renda inicial em 1820 e em parte da taxa média de crescimento dessa renda; sendo que o primeiro fator - baixa renda inicial - é o mais importante na nossa visão.

TABELA 10 - COMPARAÇÃO INTERNACIONAL DE RENDAS PER CAPITAS EM DÓLARES INTERNACIONAIS DE GEARY-KHAMIS - 1820/2008

\begin{tabular}{l|c|c|c|c|c|c|c|c}
\hline & EUA & França & $\begin{array}{c}\text { Reino } \\
\text { Unido }\end{array}$ & Argentina & Chile & México & Venezuela & Brasil \\
\hline 1820 & 1.894 & 1.710 & 2.570 & - & 1.045 & 1.144 & 692 & 908 \\
1830 & 2.073 & 1.794 & 2.635 & - & 1.000 & - & - & 892 \\
1840 & 2.392 & 2.151 & 2.999 & - & 1.131 & - & - & 852 \\
1850 & 2.721 & 2.406 & 3.511 & - & 1.404 & - & - & 988 \\
1860 & 3.282 & 2.851 & 4.265 & - & 1.648 & - & - & 999 \\
1870 & 3.683 & 2.826 & 4.807 & 1.975 & 1.944 & 1.015 & 858 & 1.300 \\
1880 & 4.797 & 3.195 & 5.239 & - & 2.622 & - & - & 1.128 \\
1890 & 5.111 & 3.580 & 6.041 & 3.243 & 2.963 & 1.524 & - & 1.208 \\
1900 & 6.164 & 4.333 & 6.768 & 4.152 & 3.306 & 2.058 & 1.237 & 1.054 \\
1925 & 9.466 & 6.278 & 7.751 & 5.906 & 4.750 & 2.875 & 3.136 & 1.379 \\
1950 & 14.406 & 7.813 & 10.455 & 7.513 & 5.529 & 3.563 & 11.243 & 2.592 \\
1975 & 24.535 & 19.523 & 17.850 & 12.238 & 6.439 & 7.772 & 15.778 & 6.471 \\
2000 & 42.892 & 30.770 & 30.666 & 12.929 & 15.533 & 10.961 & 12.705 & 8.581 \\
2008 & 46.976 & 33.484 & 35.773 & 16.567 & 19.866 & 12.022 & 15.965 & 10.030 \\
\hline
\end{tabular}

Fonte: Para o Brasil, resultados do trabalho; para os demais países Maddison (2006).

\section{O PIB brasileiro: períodos de crescimento e ciclos}

Nessa parte do trabalho faremos uma breve análise do comportamento do produto brasileiro no período 1820-2012. A análise dos ciclos econômicos tem uma longa tradição na ciência econômica, tradição essa que remonta aos primórdios da disciplina com os trabalhos dos clássicos como Adam Smith, David Ricardo, Thomas Malthus, etc. No século XX, o estudo dos ciclos eco- 
nômicos ganha novo impulso na esteira da grande depressão econômica da década de 1930. A análise das propriedades estatísticas dos ciclos econômicos também começou a receber atenção nessa época dada a recente disponibilidade de estatísticas econômicas regulares. Os autores Mitchell \& Burns (1946) identificaram várias características dos ciclos econômicos da economia dos Estados Unidos, assim como o fez Kaldor (1961) para economias em geral.

Em anos mais recentes, de 1980 até hoje, o estudo da propriedade estatística dos ciclos econômicos foi novamente impulsionada com o advento das linhas de pesquisa dos Ciclos Reais de Negócios e da macroeconomia Novo-Clássica. Trabalhos como o de Beverigde \& Nelson (1981), Nelson \& Plosser (1982), Backus \& Kehoe (1992) e Hodrick \& Prescott (1980; 1997) são referências típicas dessa linha de pesquisa. No que diz respeito ao estudo das regularidades dos ciclos econômicos brasileiros a literatura é pequena se comparada com o estrangeiro, mas crescente.

Estudando o PIB entre 1900 e 1990, Cribari-Neto (1990) e Cribari-Neto (1993) concluiu que o PIB brasileiro possui uma raiz unitária e que o componente cíclico é "pequeno" sendo que todas as flutuações seriam devidas a fatores de longo prazo. Em seu trabalho, Chauvet (2002) utiliza um modelo de mudança de regime markoviano para estudar o ciclo de negócios brasileiro tanto anualmente entre 1900 e 1999, quanto trimestralmente entre 1980:01 e 2000:01; em Chauvet (1998), a autora estuda as flutuações no produto por meio de um modelo com mudança de regime e fatores dinâmicos. Por sua vez, Ellery et al. (2002) estudam as propriedades do ciclo de negócios brasileiro no pós-segunda guerra mundial. Estudaram relações entre PIB, consumo, investimento, horas trabalhadas, etc; e simularam um modelo de equilíbrio geral dinâmico no qual concluíram que o mesmo não era capaz de replicar muitas das características dos dados brasileiros. Os autores Ellery Jr \& Gomes (2005) replicam para o caso brasileiro o estudo de Backus \& Kehoe (1992), onde esses autores coletam e analisam um conjunto de evidências a respeito dos ciclos econômicos em diversos países desenvolvidos. A conclusão de Ellery Jr \& Gomes (2005) foi a de que, em geral, os fatos estilizados básicos da literatura de ciclos de negócios são observados no Brasil.

Em seu trabalho, Sampaio (2009:46) analisou os ciclos econômicos do Brasil entre 1980 e 2008 , e concluiu que "na década de 90, ocorreram períodos de expansão mais frequentes que na década de 8o, sendo que o período de expansão mais persistente ocorreu a partir da segunda metade de 2003." Por seu turno, Silva \& Gomes (2011) a persistência das flutuações no produto brasileiro durante o século XX. Utilizando modelos ARFIMA e testes de raízes unitárias com quebras estruturais, concluíram que o PIB e o PIB per capita brasileiros apresentam alto grau de persistência. Num trabalho ao modo de Beveridge e Nelson (1981), Costa \& Bessaria (2012) analisam o comportamento de várias séries econômicas brasileiras, entre elas o PIB, a procura de "tendências estacionárias" ou "diferenças estacionárias". Os autores concluem que 
a maioria das séries econômicas brasileiras se caracterizam como diferenças estacionárias, inclusive o PIB.

Por fim, Araújo et al. (2008) tem o único trabalho nos moldes dos acima mencionados em que se analisa os ciclos econômicos e o crescimento do produto brasileiro, inclusive no século XIX. Na verdade os autores fazem um estudos dos ciclos de negócios e do crescimento brasileiro entre 1850 e 1900. Para isso usam a estimativa do PIB brasileiro entre 1850 e 1899 de Goldsmith (1986) encadeadas à estimativa de Haddad (1978) em 1900 e às estimativas oficiais em 1947. Concluíram, entre outras coisas, que entre 1850 e 2000 a volatilidade do PIB brasileiro poderia ser dividida em três fases. Uma de baixa volatilidade entre 1850 e 1875, outra de alta entre 1876 e 1975, e uma de baixa entre 1976 e 2000. Concluíram também que a volatilidade do produto brasileiro seria bastante diferente da verificada nos Estados Unidos e outros países desenvolvidos, principalmente no que diz respeito ao período pós-segunda guerra mundial. Nos países desenvolvidos o produto se mostrou menos volátil no período pós-guerra comparado ao ante-guerra, o oposto ocorreu no Brasil segundo os autores.

Um problema com esse tipo de estudo é que, rigorosamente falando, os dados pré-segunda guerra não são diretamente comparáveis aos dados pós-guerra. Por exemplo, alguns economistas afirmam que a macroeconomia keynesiana teve uma grande influencia no comportamento dos agregados econômicos como desemprego e produto no pós-segunda guerra. O argumento é de que a economia dos Estados Unidos teria ficado mais estável com o advento das políticas de estabilização keynesianas.

Entretanto, numa série de artigos na metade da década de 1980, Romer (1986a, 1986b) desafiou esse argumento afirmando que a diminuição verificada na volatilidade dos dados indica uma melhora na qualidade dos próprios dados e não do desempenho da economia. Para sustentar seu argumento, a autora construiu séries de dados para o período pós-guerra que sofreriam das mesmas "deficiências" dos dados pré-guerra. Concluiu disso que a economia norte-americana seria apenas "ligeiramente" mais estável no pós-guerra do que o era no pré-guerra. No caso específico do Brasil, acreditamos que tal "ilusão" dos dados deve também ser considerada quando da análise comparativa entre o PIB no pós-guerra com o do pré-guerra, principalmente no que diz respeito ao século XIX.

\subsection{O PIB brasileiro e suas fases de crescimento - 1820/2012}

No Gráfico 7, mostramos as fases “aparentes” do processo de crescimento econômico brasileiro entre 1820 e 2012. Tal gráfico foi construído simplesmente tomando uma tendência linear do log natural do PIB entre períodos de tempo 
distintos que pareciam diferir dos outros períodos em termos de inclinação da reta ajustada. Não optamos por aplicar um Teste de Chow tradicional para identificar os pontos de quebra, pois parece consensual na literatura, como em Cribari-Neto (1990, 1993), Abras et al. (2004), Dias \& Castro Júnior (2003) e Silva \& Gomes (2011) entre outros, de que o PIB brasileiro possui uma raiz unitária ${ }^{14}$. Tal fato tornaria infrutífero tal exercício - Teste de Chow - porque os coeficientes estimados na tendência linear seriam viesados e inconsistentes, ou seja, a regressão seria espúria. Com essas resalvas em mente, identificamos sete fases no crescimento do produto real agregado brasileiro: 1820-1875 (56 anos), com crescimento médio de 2,70\% a.a.; 1876-1905 (30 anos), com 2,29\% a.a.; 1906-1945 (40 anos), com 4,34\% a.a.; 1946-1957 (12 anos), com 6,33\% a.a.; 1958-1978 (21 anos), com 7,39\% a.a.; 1979-2003 (25 anos), com 2,26\% a.a.; e 2004-2012 (9 anos), com crescimento médio de 3,80\% a.a. A taxa média do período como um todo (1820-2012, 193 anos) foi de 3,71\% a.a.

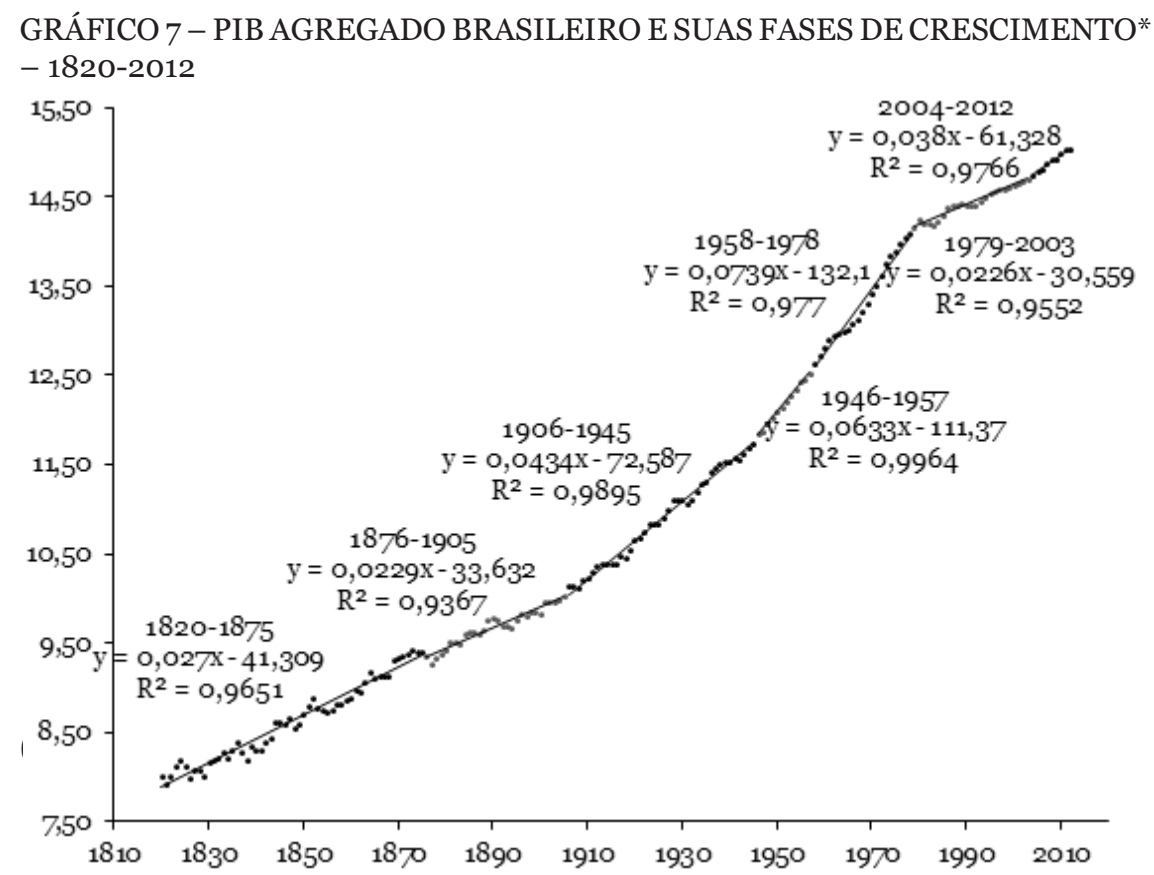

Fonte: Elaboração própria a partir dos resultados do trabalho.

*Nota: Logaritmo natural do PIB real agregado em milhões de reais constantes de 2008.

Repetindo o mesmo exercício para o PIB per capita, no Gráfico 8 nós identificamos seis fases de crescimento, a saber: 1820-1875 (56 anos), com taxa 
média de crescimento de 1,21\% a.a.; 1876-1919 (44 anos), com 0,36\% a.a.; 1920-1957 (38 anos), com 3,02\% a.a.; 1958-1978 (21 anos), com 4,64\% a.a.; 1979-2003 (25 anos), com 0,48\% a.a.; e 2004-2012 (9 anos), com taxa média de crescimento de $2,93 \%$ a.a. A grosso modo as taxas de crescimento da renda per capita brasileira não foram ruins, exceto para os períodos 18761919 e 1979-2003, totalizando 69 anos em que a taxa média de crescimento da renda per capita foi o,4035\% a.a. (média ponderada dos dois períodos). A taxa média do período como um todo (1820-2012, 193 anos) foi de 1,73\% a.a. (média ponderada pela duração dos períodos). Essa taxa de 1,73\% a.a. para o crescimento médio da renda per capita brasileira (em reais) cofirma nossa constatação anterior de que a atual baixa renda per capita brasileira, comparada aos países desenvolvidos, deve-se mais ao baixo nível da renda inicial do país no começo do século XIX do que ao seu desempenho econômico

GRÁFICO 8 - PIB PER CAPITA BRASILEIRO E SUAS FASES DE CRESCIMEN$\mathrm{TO}^{*}-1820-2012$

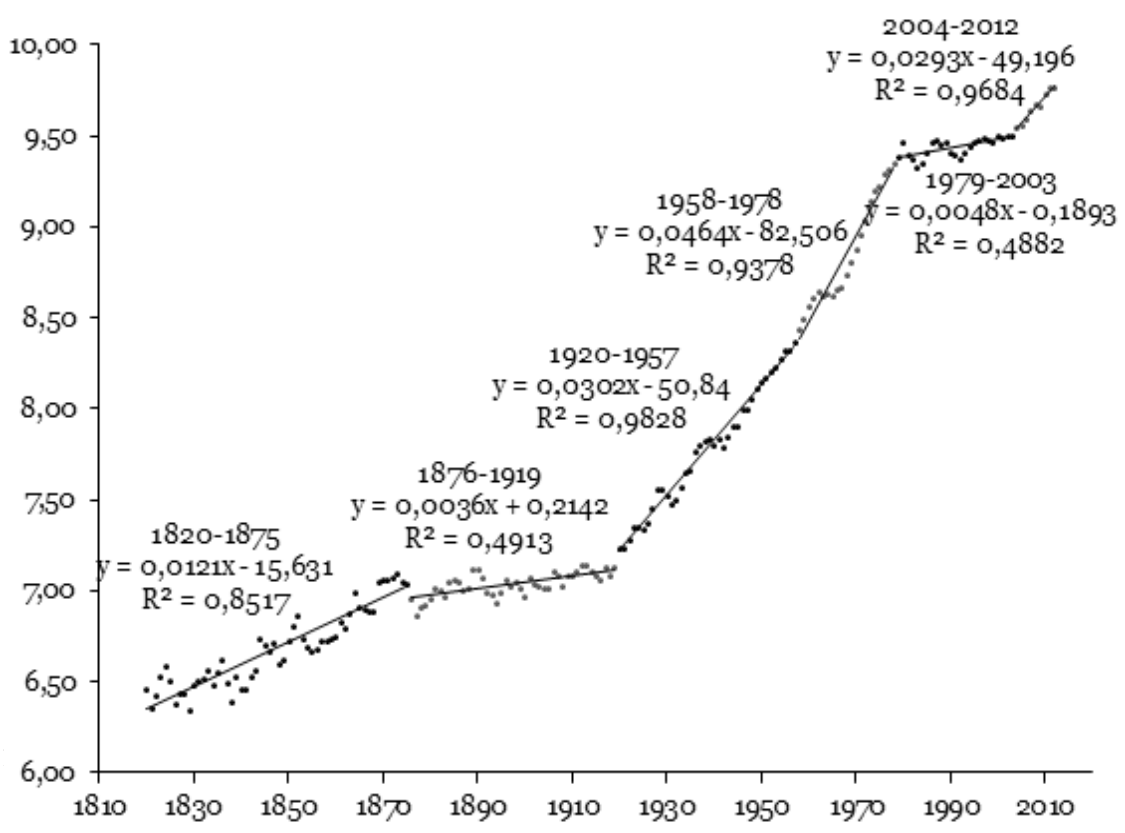

Fonte: Elaboração própria a partir dos resultados do trabalho.

* Nota: Logaritmo natural do PIB per capita em reais constantes de 2008.

Da mesma forma, fizemos o mesmo exercício no Gráfico 9 em relação ao PIB por trabalhador entre 1820 e 2011. Identificamos sete fases de crescimento distintas, tais foram: 1820-1875 (56 anos), com taxa média de crescimento de 1,24\% a.a.; 1876-1905 (30 anos), com 0,89\% a.a.; 1906-1926 (21 anos), com 
3,5\% a.a.; 1927-1945 (19 anos), com o,86\% a.a.; 1946-1975 (30 anos), com 4,06\% a.a.; 1976-2004 (29 anos), com -0,12\% a.a.; e 2005-2011 (7 anos), com taxa média de crescimento de 2,9\% a.a. A taxa média do período como um todo (1820-2011, 192 anos) foi de 1,69\% a.a. (média ponderada pela duração dos períodos), o que é uma boa taxa. Entretanto, é claro o fraco desempenho do produto por trabalhador que a economia brasileira teve entre 1976 e 2004, onde o mesmo ficou praticamente estagnado com taxa média de crescimento de -0,12\% a.a. Os dados de força de trabalho que nós utilizamos foram retirados da PNAD do IBGE e dos censos demográficos nacionais. Os dados de força de trabalho das contas nacionais registram uma população ocupada menor que a PNAD, mas a tendência das duas séries é bastante semelhante o que melhoraria pouco o desempenho do produto por trabalhador no Brasil ${ }^{15}$. É consenso na literatura que o desempenho da produtividade da mão de obra brasileiro foi muito ruim nesse período.

GRÁFICO 9 - PIB POR TRABALHADOR BRASILEIRO E SUAS FASES DE CRESCIMENTO* $^{*}$ 1820-2012

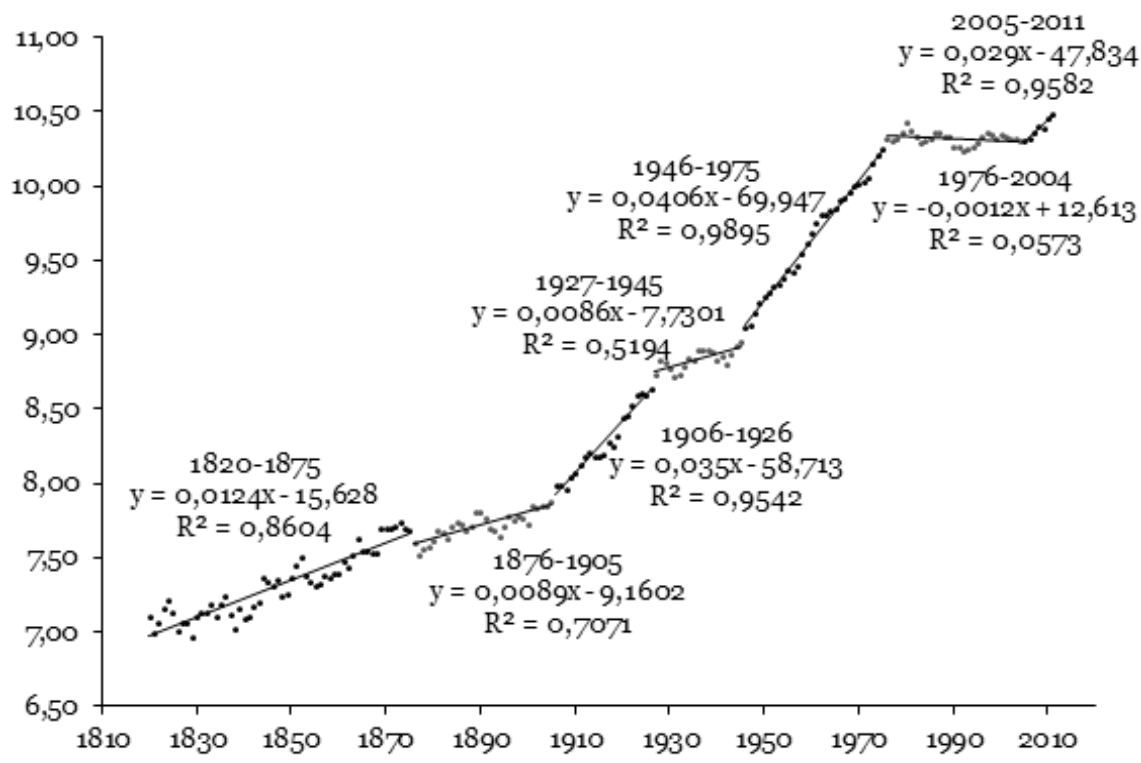

Fonte: Elaboração própria a partir dos resultados do trabalho.

* Nota: Logaritmo natural do PIB per capita em reais constantes de 2008.

\subsection{Comportamento cíclico do PIB brasileiro - 1820/2012}


Para extrair o componente cíclico das séries, nós utilizamos o filtro de Hodrick e Prescott $(1980,1997)$ - Filtro HP - com o valor do parâmetro lâmbda $(\lambda)$ de suavização igual a 100, como foi sugerido pelos autores. Na Tabela 11, nós mostramos o desvio-padrão e a autocorrelação dos ciclos para alguns períodos selecionados.

Diferente do que Araújo et al. (2008) encontraram em seu estudo, a Tabela 11 mostra a volatilidade dos ciclos, medida pelo desvio-padrão, caindo persistentemente de 1820 até 2012. Entretanto, a diferença dos dois resultados deve-se a inclusão do século XIX na análise, pois para o século XX os resultados dos dois estudos são os mesmos dado que se baseiam no mesmo conjunto de dados para esse período. Para o século XIX, os autores usaram a estimativa do PIB real de Goldsmith (1986), o desvio-padrão do ciclo da estimativa de Goldsmith entre 1850 e 1899 é de 4,93\%, enquanto que na nossa estimativa para o mesmo período o desvio-padrão é de 5,46\%. Então desse fato resulta a diferença dos dois estudos no período relativo ao século XIX. No que diz respeito a persistência dos ciclos, persistência essa medida pela autocorrelação de primeira ordem, os dois trabalhos, o nosso e o de Araújo et al. (2008), indicam que a persistência dos ciclos aumentaram com o decorrer do tempo. No Gráfico 10, mostramos o ciclo extraído do log natural do PIB real entre 1820 e 2012. O ciclo das outras duas séries, PIB per capita e PIB por trabalhador, é bem semelhante ao do PIB agregado, então não as colocamos no gráfico.

TABELA 11 - DESVIO-PADRÃO E PERSISTÊNCIA DOS CICLOS ECONÔMICOS* NO BRASIL - 1820/2012

\begin{tabular}{|c|c|c|c|c|c|c|}
\hline \multirow[b]{2}{*}{ Período } & \multicolumn{2}{|c|}{ PIB Agregado } & \multicolumn{2}{|c|}{ PIB per capita } & \multicolumn{2}{|c|}{ PIB por trabalhador } \\
\hline & \begin{tabular}{|l} 
Desvio \\
Padrão (\%)
\end{tabular} & $\begin{array}{l}\text { Auto } \\
\text { correlação }\end{array}$ & \begin{tabular}{|l|} 
Desvio \\
Padrão (\%)
\end{tabular} & \begin{tabular}{|l} 
Auto \\
correlação
\end{tabular} & \begin{tabular}{|l|} 
Desvio \\
Padrão (\%)
\end{tabular} & $\begin{array}{l}\text { Auto } \\
\text { correlação }\end{array}$ \\
\hline 1820-1875 & 6,46 & 0,3602 & 6,48 & 0,3646 & 6,46 & 0,3609 \\
\hline 1876-1905 & 4,76 & 0,4664 & 4,71 & 0,4575 & 4,75 & 0,4659 \\
\hline $1906-1946$ & 4,37 & 0,5061 & 4,39 & 0,5078 & 4,53 & 0,5311 \\
\hline $1947-1980$ & 4,08 & 0,7566 & 4,07 & 0,7450 & 3,47 & 0,6172 \\
\hline 1981-2012 & 3,00 & 0,5741 & 2,98 & 0,5709 & 3,05 & 0,6202 \\
\hline 1820-2012 & 4,89 & 0,4581 & 4,89 & 0,4577 & 4,85 & 0,4504 \\
\hline
\end{tabular}

Fonte: Elaboração própria a partir dos resultados do trabalho.

*Nota: Ciclos extraídos pela aplicação do Filtro HP $\operatorname{com} \lambda=100$ ao $\log$ natural das séries.

Na comparação entre os períodos pré-primeira guerra (1850-1914), inter-guerras (1920-1939), e pós-segunda guerra (1950-1985) que Araújo, Carpena e Cunha (2008, p. 569) fizeram na Tabela 6 de seu trabalho, o período pré- 
-primeira guerra teve desvio-padrão maior que os dois outros. O mesmo ocorre em nosso trabalho, com a diferença que na tabela deles o desvio-padrão para o período 1850-1914 é de 4,80\%, enquanto na nossa estimativa o desvio-padrão é de 5,08\% para o mesmo período. Para o período 1920-1939 o desvio-padrão é de 4,64\%, e para o período 1950-1985 é de 4,35\%.

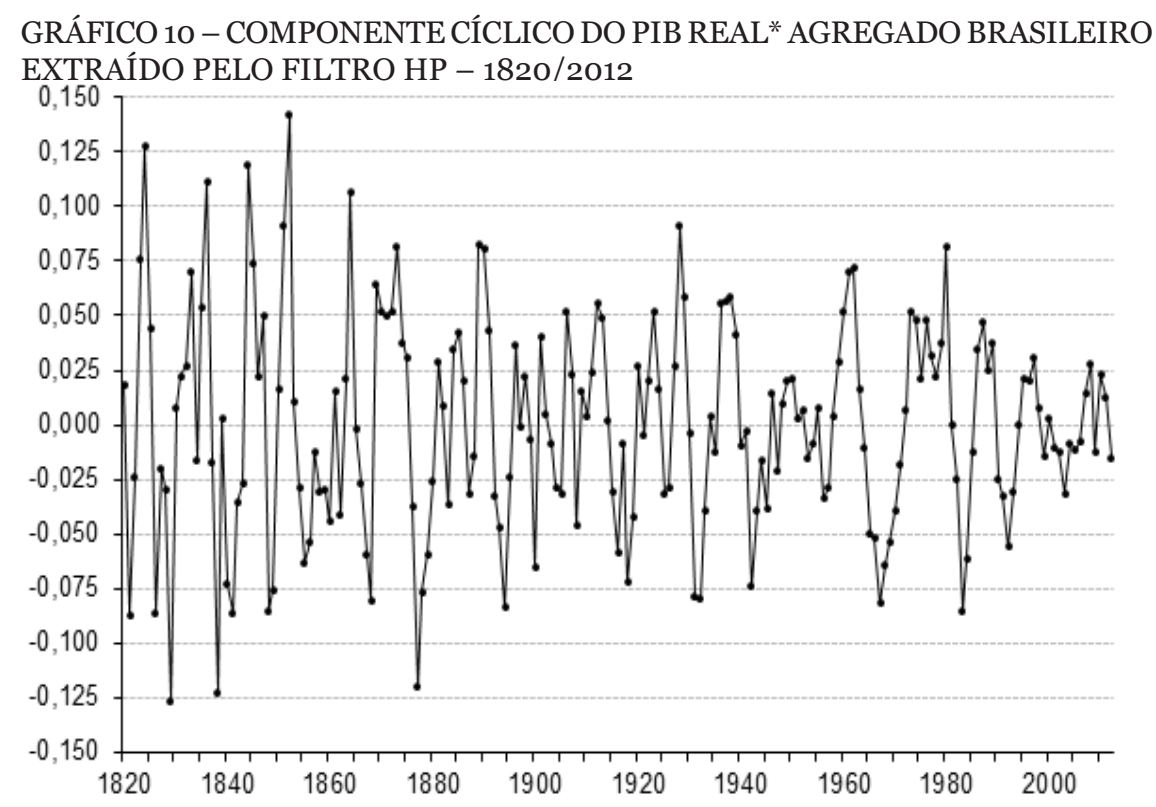

Fonte: Elaboração própria a partir dos resultados do trabalho.

*Nota: Ciclo extraído pela aplicaccão do Filtro HP $\operatorname{com} \lambda=100$ ao log natural do PIB em milhões de reais constantes de 2008.

Nas Tabelas 12 e 13, nós mostramos os períodos de expansão e recessão da economia brasileira entre 1820 e 2012. Para isso usamos o mesmo procedimento de Araújo et al. (2008: 570) para obter as fases de expansão e recessão. Seja ct é o ciclo extraído pelo Filtro HP, então chamamos de expansão os períodos em que ct - ct-1 > o, e de recessão os períodos em que ct - ct-1 $\leq$ o. Identificamos 47 períodos de expansão com duração média de 2,06 anos cada um. Os períodos mais longos foram de seis anos, os quais ocorreram apenas duas vezes (1957-1962 e 1968-1973); ocorreram ainda quatro períodos de quatro anos de expansão, sete de três, catorze de dois, e vinte períodos de um ano de expansão. Com relação aos períodos de recessão, identificamos 48 períodos de recessão com duração média de 1,98 ano cada um. Os períodos mais longos foram de cinco anos, os quais também ocorreram apenas duas vezes (1890-1894 e 1963-1967); ocorreram ainda cinco períodos de quatro 
anos de expansão, quatro de três, dezesseis de dois, e vinte e um períodos de um ano de expansão.

TABELA 12 - FASES CÍCLICAS DO LOG NATURAL DO PIB AGREGADO - 18212012

\begin{tabular}{lllllllllllllllll}
\hline Ano & Fase & Ano & Fase & Ano & Fase & Ano & Fase & Ano & Fase & Ano & Fase \\
\hline 1821 & - & 1853 & - & 1885 & + & 1917 & + & 1949 & + & 1981 & - \\
1822 & + & 1854 & - & 1886 & - & 1918 & - & 1950 & + & 1982 & - \\
1823 & + & 1855 & - & 1887 & - & 1919 & + & 1951 & - & 1983 & - \\
1824 & + & 1856 & + & 1888 & + & 1920 & + & 1952 & + & 1984 & + \\
1825 & - & 1857 & + & 1889 & + & 1921 & - & 1953 & - & 1985 & + \\
1826 & - & 1858 & - & 1890 & - & 1922 & + & 1954 & + & 1986 & + \\
1827 & + & 1859 & + & 1891 & - & 1923 & + & 1955 & + & 1987 & + \\
1828 & - & 1860 & - & 1892 & - & 1924 & - & 1956 & - & 1988 & - \\
1829 & - & 1861 & + & 1893 & - & 1925 & - & 1957 & + & 1989 & + \\
1830 & + & 1862 & - & 1894 & - & 1926 & + & 1958 & + & 1990 & - \\
1831 & + & 1863 & + & 1895 & + & 1927 & + & 1959 & + & 1991 & - \\
1832 & + & 1864 & + & 1896 & + & 1928 & + & 1960 & + & 1992 & - \\
1833 & + & 1865 & - & 1897 & - & 1929 & - & 1961 & + & 1993 & + \\
1834 & - & 1866 & - & 1898 & + & 1930 & - & 1962 & + & 1994 & + \\
1835 & + & 1867 & - & 1899 & - & 1931 & - & 1963 & - & 1995 & + \\
1836 & + & 1868 & - & 1900 & - & 1932 & - & 1964 & - & 1996 & - \\
1837 & - & 1869 & + & 1901 & + & 1933 & + & 1965 & - & 1997 & + \\
1838 & - & 1870 & - & 1902 & - & 1934 & + & 1966 & - & 1998 & - \\
1839 & + & 1871 & - & 1903 & - & 1935 & - & 1967 & - & 1999 & - \\
1840 & - & 1872 & + & 1904 & - & 1936 & + & 1968 & + & 2000 & + \\
1841 & - & 1873 & + & 1905 & - & 1937 & + & 1969 & + & 2001 & - \\
1842 & + & 1874 & - & 1906 & + & 1938 & + & 1970 & + & 2002 & - \\
1843 & + & 1875 & - & 1907 & - & 1939 & - & 1971 & + & 2003 & - \\
1844 & + & 1876 & - & 1908 & - & 1940 & - & 1972 & + & 2004 & + \\
1845 & - & 1877 & - & 1909 & + & 1941 & + & 1973 & + & 2005 & - \\
1846 & - & 1878 & + & 1910 & - & 1942 & - & 1974 & - & 2006 & + \\
1847 & + & 1879 & + & 1911 & + & 1943 & + & 1975 & - & 2007 & + \\
1848 & - & 1880 & + & 1912 & + & 1944 & + & 1976 & + & 2008 & + \\
1849 & + & 1881 & + & 1913 & - & 1945 & - & 1977 & - & 2009 & - \\
1850 & + & 1882 & - & 1914 & - & 1946 & + & 1978 & - & 2010 & + \\
1851 & + & 1883 & - & 1915 & - & 1947 & - & 1979 & + & 2011 & - \\
1852 & + & 1884 & + & 1916 & - & 1948 & + & 1980 & + & 2012 & - \\
\hline
\end{tabular}

Fonte: Elaboração própria a partir dos resultados do trabalho. 
TABELA 13 - FASES DE EXPANSÃO E RECESSÃO DO LOG NATURAL DO PIB AGREGADO - 1821-2012

\begin{tabular}{lccc}
\hline Duração dos períodos (anos) & Períodos de expansão & Períodos de recessão \\
\hline 6 & 2 & 0 \\
5 & 0 & 2 \\
4 & 4 & 5 \\
3 & 7 & 4 \\
& 2 & 14 & 16 \\
& 1 & 20 & 21 \\
\hline Total & 47 & 48 \\
\hline Anos totais & 97 & 95 \\
\hline Duração Média & 2,06 & 1,98 \\
\hline
\end{tabular}

Fonte: Elaboração própria a partir dos resultados do trabalho.

\section{Considerações Finais}

O objetivo desse trabalho foi analisar o comportamento da série temporal do PIB brasileiro entre 1820 e 2012 no que diz respeito ao seu comportamento cíclico e períodos de crescimento econômico. Outro objetivo que surgiu com isso foi o de estimar o PIB nominal e real do Brasil entre 1820 e 1899, dada a ausência de estimativas que cobrissem esse período de forma continua.

Identificamos sete fases no crescimento do produto real agregado brasileiro: 1820-1875 (56 anos), com crescimento médio de 2,70\% a.a.; 1876-1905 (30 anos), com 2,29\% a.a.; 1906-1945 (40 anos), com 4,34\% a.a.; 1946-1957 (12 anos), com 6,33\% a.a.; 1958-1978 (21 anos), com 7,39\% a.a.; 1979-2003 (25 anos), com 2,26\% a.a.; e 2004-2012 (9 anos), com crescimento médio de $3,80 \%$ a.a. A taxa média do período como um todo (1820-2012, 193 anos) foi de $3,71 \%$ a.a. (média ponderada pela duração dos períodos). Na análise do PIB per capita, identificamos seis fases de crescimento, a saber: 1820-1875 (56 anos), com taxa média de crescimento de 1,21\% a.a.; 1876-1919 (44 anos), com 0,36\% a.a.; 1920-1957 (38 anos), com 3,02\% a.a.; 1958-1978 (21 anos), com 4,64\% a.a.; 1979-2003 (25 anos), com 0,48\% a.a.; e 2004-2012 (9 anos), com taxa média de crescimento de $2,93 \%$ a.a.

No que diz respeito à volatilidade dos ciclos, essa foi em geral decrescente quando medida pelo desvio-padrão dos ciclos extraídos pelo Filtro HP: o desvio-padrão foi de $6,46 \%$ no período $1820-1875,4,76 \%$ no período 1876 - 
1905, 4,37\% no período 1906-1946, 4,o8\% no período 1947-1980, e 3,00\% no período 1981-2012. Também concluímos que, em termos da análise da série temporal do PIB apenas, a atual baixa renda per capita brasileira depende em parte do baixo nível da renda inicial em 1820 e em parte da taxa média de crescimento dessa renda; sendo que o primeiro fator - baixa renda inicial - é o mais importante na nossa visão.

\section{Referências Bibliográficas}

ABRAS, A. L.; BORGES, B.; SEKKEL, R. (2004). "Breaking trend, Lagrange multiplier test statistic and the presence of a unit root in the Brazilian gross domestic product.” Applied Economics Letters, v. 11(6).

ABREU, M. DE P.; LAGO, L. A. C. DO. (2012). “A economia brasileira no Império, 1822-1889”. Texto para Discussão n. 584. Departamento de Economia da Pontifícia Universidade Católica.

JUNIOR, L. de A. (1920). O custo da vida na cidade do Rio de Janeiro. Rio de Janeiro: Imprensa Nacional.

AGUIRRE, A.; FERREIRA, A. H. B. (2001). "The (in)existence of a unit root in Brazilian gross domestic product.” Applied Economics Letters, v. 8(10).

ARAÚJO, E.; CARPENA, L.; CUNHA, A. B. (2008). "Brazilian Business Cycles and Growth from 1850 to 2000.” Estudos Econômicos 38(3).

BACKUS, D.; KEHOE, P. (1992). "International evidence on the historical properties of business cycles.” American Economic Review, v. 82(4).

BALASSA, Bella. (1969). “The purchasing-power parity doctrine: a reappraisal.” In. COOPER. International finance. Penguim.

BEVERIDGE, S.; NELSON, C. R. (1981). “A new approach to decomposition of economic time series into permanent and transitory components with particular attention to measurement of the business cycle." Journal of Monetary Economics, v. 7(2).

BUESCU, M. (1973). 300 anos de inflação. Rio de Janeiro: APEC. . (1977). Evolução econômica do Brasil. Rio de Janeiro: APEC.

APEC. . (1979). Brasil, disparidades de renda no passado. Rio de Janeiro:

CARREIRA, L. de C. (1889). História financeira e orçamentária do Império do Brasil desde a sua fundação. Rio de Janeiro: Imprensa Nacional.

CASTRO, S. de; GONÇALVES, F. (2010). History or path dependence in mixed-Poisson growth: Brazil, 1822-2000, and USA, 1869-1996, with an estimate of the world mixing distribution at start-up. Brasília: Texto para Discussão n. 332, Departamento de Economia da Universidade de Brasília. 
CAVALCANTI, Amaro. (1890). "Resenha financeira do Ex-Império do Brasil em 1889." Rio de Janeiro: Imprensa Nacional.

CHAUVET, M. (2002). “The Brazilian business and growth cycles”. Revista Brasileira de Economia, v. 56(1).

. (1998). "An Econometric Characterization of Business Cycle Dynamics with Factor Structure and Regime Switches”. International Economic Review, v. 39(4).

COSTA, R. F. R.; BESSARIA, C. N. (2012). "Caracterização das flutuações das séries macroeconômicas brasileiras: um estudo empírico e metodológico.” Revista Economia e Desenvolvimento, v. 11(1).

COASTWORTH, J. H. (1978). "Obstacles to economic growth in nineteenth century Mexico”. American Historical Review, v. 83(1).

CRIBARI-NETO, F. (1990). “O comportamento estocástico do produto no Brasil”. Pesquisa e Planejamento Econômico, v. 20( 2).

. (1993). “The cyclical component in Brazilian GDP”. Revista Brasileira de Econometria, v. 13(1).

DIAS, J.; CASTRO JR., V. J. DE. (2003). “Análise de quebra estrutural da formação bruta de capital fixo no Brasil”. Revista de Economia, v. 29.

HADDAD, C. L.; CONTADOR, C. R. (1975). "Produto, moeda e preços: Brasil 18611970.” Revista Brasileira de Estatística, v. 36(143).

ELLERY Jr., R.; GOMES, V. (2005). “Ciclo de negócios no Brasil durante o século XX: uma comparação com a evidência internacional.” Revista Economia, v. 6(1).

ELLERY Jr., R.; GOMES, V.; SACHSIDA, A. (2002). "Business cycle fluctuations in Brazil.” Revista Brasileira de Economia, v. 56(2).

ENGERMAN, S. L.; SOKOLLOF, K. L. (1997). "Factor endowments, institutions and differential paths of growth among New World economies.” In: HABER, S. (org.). How Latin America Fell Behind: Essays on the economic history of Brazil and Mexico, 1800-1914. Stanford: Stanford University Press.

FAVA, V. L.; CATI, R. C. (1995). "Mudanças no comportamento do PIB brasileiro: uma abordagem econométrica.” Pesquisa e Planejamento Econômico, v. 25(2).

FURTADO, C. (1976). Formação econômica do Brasil. São Paulo: Fundo de Cultura.

GAMA, M. J. N. DA. (1823). Exposição do estado da fazenda pública. Rio de Janeiro: Tipografia Nacional.

GOLDSMITH, R. W. (1986). Brasil 1850-1984: desenvolvimento financeiro sob um século de inflação. São Paulo: HARBRA.

GRETL 1.9.10. (2012). Gnu Regression, Econometrics and Time-series Library.

HADDAD, C. L. (1978). Crescimento do produto real no Brasil 19oo-1947. Rio de Janeiro: Fundação Getúlio Vargas.

HILLS, S.; THOMAS, R.; DIMSDALE, N. (2010). "The UK recession in context: what do three centuries of data tell us?” London: Bank of England Quarterly Bulletin.

HODRICK, R. J.; PRESCOTT, E. C. (1980). "Post-war US business cycles: an empirical investigation.” Chicago: Discussion Paper n. 451, Northwestern University. 
. (1997). "Postwar U.S. business cycles: an empirical investigation." Journal of Money, Credit and Banking, v. 29(1).

IPEADATA. (2012). Banco de dados do Instituto de Pesquisas Aplicadas. Rio de Janeiro. URL [on-line]: http://www.ipeadata.gov.br

KALDOR, N. (1961). “Capital accumulation and economic growth.” In: LUTZ, F. A.; HAGUE, D. C. (eds.). The theory of capital. Londres: Palgrave Macmillan.

LEFF, N. R. (1972). “Estimativa da renda provável no Brasil no século XIX com base nos dados sobre a moeda”. Revista Brasileira de Economia, v. 26(1).

(1991). Subdesenvolvimento e Desenvolvimento no Brasil: estrutura e mudança econômica 1822-1947. Vol. 1. Rio de Janeiro: Expressão e Cultura.

LOBO, E. M. L. (1971). "Evolução dos preços e do padrão de vida no Rio de Janeiro, 1820-1930". Revista Brasileira de Economia, v. 25(4).

LUZ, N. V.; PELÁEZ, C. M. (1972). "Economia e História: o encontro entre os dois campos do conhecimento.” Revista Brasileira de Economia, v. 26(3).

MADDISON, A. (2006). The World Economy. Paris: OECD.

MITCHELL, B. R. (1988). British Historical Statistics. Reino Unido: Cambridge University Press.

MITCHELL, W. C.; BURNS, A. F. (1946). Measuring business cycles. New York: National Bureau of Economic Research.

MORTARA, G. (1941). "Sobre a utilização do Censo Demográfico para a Reconstrução das Estatísticas do Movimento da População do Brasil.” Revista Brasileira de Estatística, v. 3(5).

NELSON, C.; PLOSSER, C. (1982). "Trends and random walks in macroeconomic time series." Journal of Monetary Economics, v. 10(2).

ONODY, O. (1960). A inflação brasileira 1820-1958. Rio de Janeiro.

PELÁEZ, M. C.; SUZIGAN, W. (1976). História Monetária do Brasil: análise da política, comportamento e instituições monetárias. Rio de Janeiro: IPEA.

RANDALL, L. (1977). A comparative economic history of Latin America, v. 3. New York: Columbia University Press.

REIS, E. J. (2008). Renda per capita dos municípios brasileiros circa 1872. Trabalho não publicado, Núcleo de Estudos Espaciais Sistêmicos.

ROMER, C. D. (1986a). "Spurious volatility in historical unemployment data." Journal of Political Economy, v. 94(1).

. (1986b). "Is the stabilization of the postwar economy a figment of the data?” American Economic Review, v. 76(3).

SAMPAIO, A. (2009). “Análises de ciclos econômicos no Brasil: 1980-2009.” Economia e Tecnologia, v. 5(3).

DA SILVA, C. G.; GOMES, F. A. R. (2011). "A Persistência das Flutuações no Produto: Uma Análise Secular do Crescimento Econômico Brasileiro”. Revista Economia, v. 12(3).

VIEIRA, T. Dorival. (1947). “A evolução do sistema monetário brasileiro”. Revista 
TOMBOLO, A. G.; SAMPAIO, A. V. O PIB Brasileiro nos séculos XIX e XX...

de Administração, v. 1(2).

Paulo: IPE/USP.

(1981). A evolução do sistema monetário brasileiro. São

VILlELA, A. V.; SUZIGAN, W. (1973). Política do governo e Crescimento da Economia Brasileira, 1889-1945. Rio de Janeiro: IPEA.

Recebido em: 27 de março de 2013

Aceito em: 21 de maio de 2014 